\title{
Development of a New Boundary Layer Control Technique for Automotive Wind Tunnel Testing
}

\author{
A Thesis by \\ Thomas Elmer Farrell \\ B.S., Wichita State University, 2003
}

Submitted to the College of Engineering and the faculty of the Graduate School of

Wichita State University in partial fulfillment of

the requirement for the degree of

Master of Science

December 2005 


\section{Development of a New Boundary Layer Control Technique for Automotive Wind Tunnel Testing}

I have examined the final copy of this thesis for form and content and recommend that it be accepted in partial fulfillment of the requirements for the degree of Master of Science with a major in Aerospace Engineering

Dr. L. Scott Miller, Committee Chair

We have read this thesis

And recommend its acceptance:

Dr. Gawad Nagati, Committee Member

Dr. Don Malzahn, Committee Member 


\section{DEDICATION}

To My Family and Friends:

Without whom I never could have become the person I am today. 


\section{ACKNOWLEDGEMENTS}

Special thanks and appreciation to my advisor Dr. Miller, for his helpful insights and encouragement throughout this year. His knowledge and attitude towards learning made my experience both challenging and enjoyable. Thanks to John Laffen, Eric Clower, and the entire wind tunnel staff for their helping me in being able to successfully build and test this work. And also for the chance to work in a wind tunnel, an opportunity I hope to have again someday. Finally, my sincerest gratitude for my fiancée

Jennifer Gessler for her patience, love, and encouragement in all things this year. 


\begin{abstract}
Many different boundary layer control techniques are used in ground vehicle aerodynamic testing including suction, blowing, ground-boards, and rolling roads. In this paper an alternative boundary layer control method is discussed. Low momentum flow in the boundary layer can be energized using circulation from a rotating cylinder protruding through the floor. A comparison study shows that this application, if effective, may be a more cost-efficient solution than current road vehicle boundary layer control techniques. A pilot tunnel test was performed in the WSU Boundary Layer Tunnel with the results showing a boundary layer profile with an initial momentum thickness of 0.098 in. could be reduced by $40-45 \%$ with rotational velocities of approximately $5000 \mathrm{rpm}$. Following this successful test, a full scale test performed in the WSU Walter H. Beech Memorial Wind Tunnel demonstrated the feasibility of the concept. An initial momentum thickness of 0.1445 in. was reduced $29 \%$ with a rotational velocity of $3900 \mathrm{rpm}$. The results found seem to indicate this technique would be a very viable option provided certain aspects including cylinder balance, sizing, and rotational velocity could be optimized in future testing.
\end{abstract}




\section{TABLE OF CONTENTS}

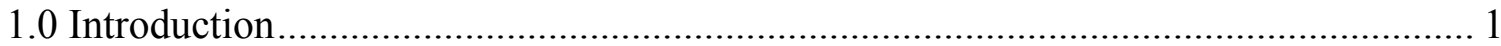

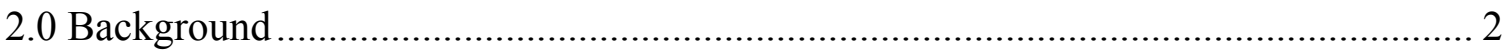

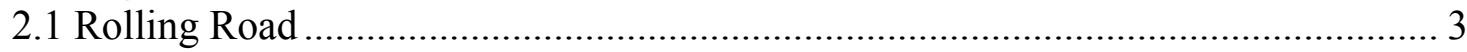

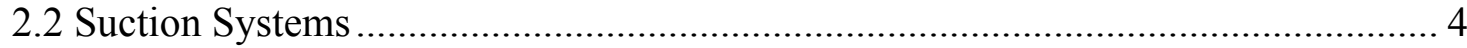

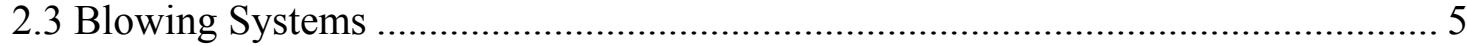

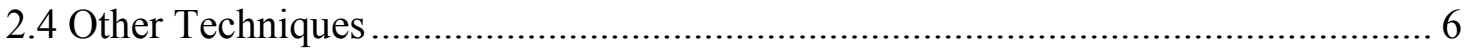

3.0 Proposed Boundary Layer Control Concept ……….......................................... 8

4.0 Experimental Boundary Layer Measurements......................................................... 13

4.1 Boundary Layer Tunnel Pilot Study ................................................................ 13

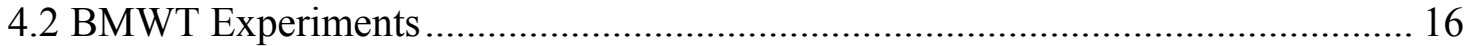

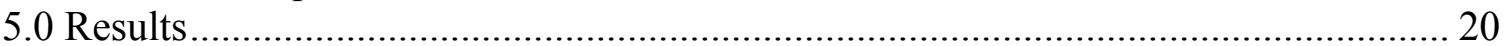

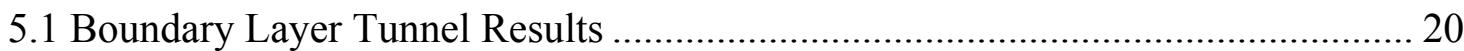

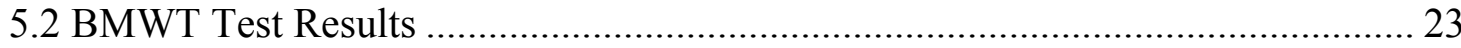

5.2.1 Tunnel Velocity Sensitivity Results........................................................... 25

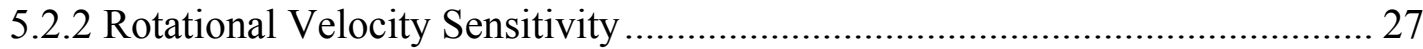

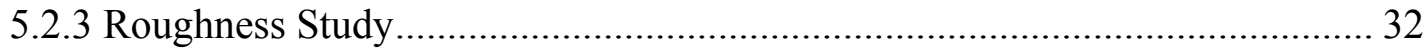

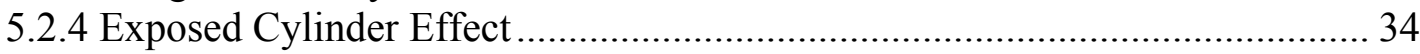

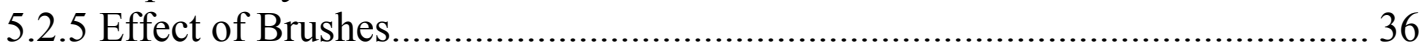

5.3 Discussion of Uncertainties .............................................................................. 38

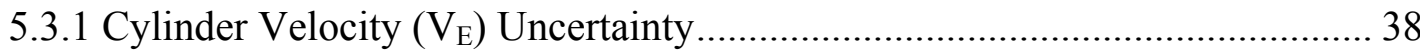

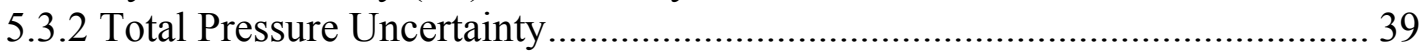

5.3.3 Tunnel Velocity $\left(\mathrm{V}_{\infty}\right)$ Uncertainty .................................................................. 41

5.3.4 Local Static Pressure Uncertainty .................................................................. 41

6.0 Design Considerations ...................................................................................... 43

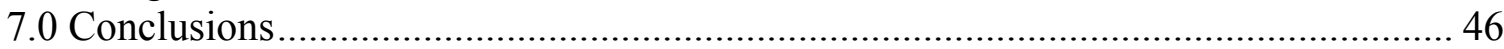

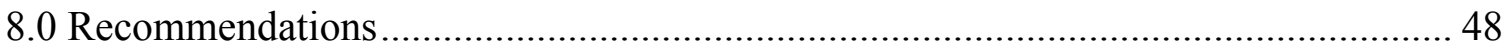

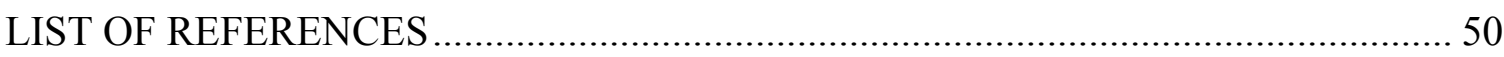

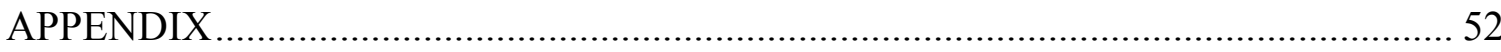

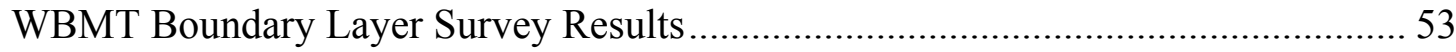




\section{LIST OF TABLES}

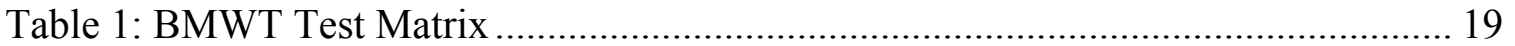




\section{LIST OF FIGURES}

Figure 1: Boundary Layer Control Techniques ${ }^{3}$.................................................... 3

Figure 2: New Boundary Layer Control Concept Sketch............................................... 8

Figure 3: Velocity Profile Manipulation...................................................................... 9

Figure 4: Lift Generated by a Rotating Cylinder in Uniform Flow ${ }^{2}$.............................. 10

Figure 5: Comparison of Potential and Experimental Circulation Values vs. Rotational Velocity 11

Figure 6: Boundary Layer Tunnel............................................................................. 14

Figure 7: Experimental Boundary Layer Control Setup ................................................ 15

Figure 8: Walter H. Beech Memorial Wind Tunnel (BMWT) Diagram ${ }^{13}$...................... 16

Figure 9: BMWT Experimental Apparatus............................................................. 18

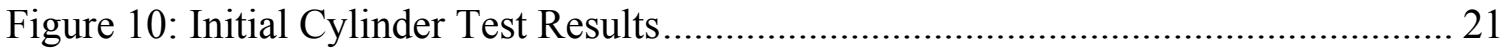

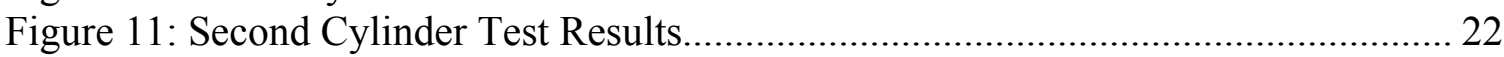

Figure 12: Momentum Thickness Reduction vs. Rotational Velocity, $\omega \ldots \ldots \ldots \ldots \ldots \ldots \ldots \ldots \ldots . . .23$

Figure 13: BMWT Nominal Boundary Layer Profile.................................................... 24

Figure 14: Boundary Layer Profile Comparison …………………………………….. 25

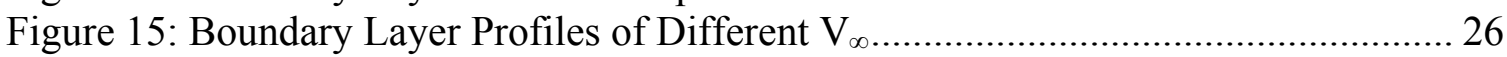

Figure 16: Non-Dimensional Boundary Layer Profiles of Different $V_{\infty} \ldots \ldots \ldots \ldots \ldots \ldots \ldots \ldots \ldots \ldots . . .26$

Figure 17: Total Pressure Profiles for Different $\omega$ Values ………………………….... 28

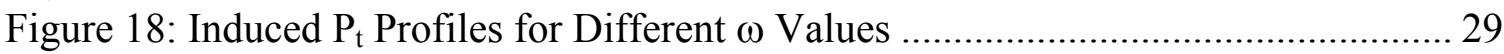

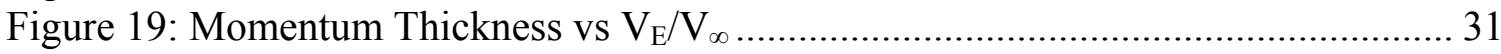

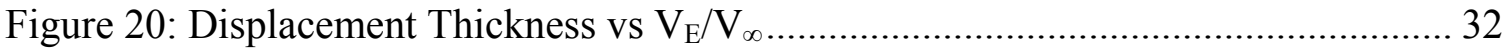

Figure 21: Boundary Layer Thickness: Roughness Effect ............................................. 33

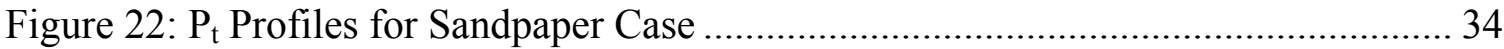

Figure 23: Boundary Layer Thickness: Effect of Exposed Height, h............................. 35

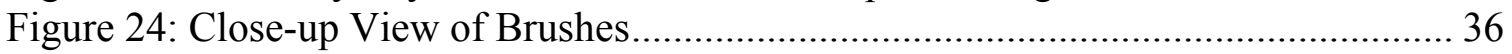

Figure 25: Reduction in Momentum Thickness by Adding Brushes................................ 37

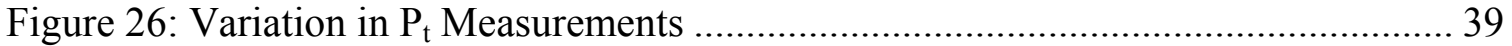

Figure 27: Results for 60mph Case Extrapolated to Higher $\mathrm{V}_{\mathrm{E}} / \mathrm{V}_{\infty}$ Values ..................... 44

Figure 28: Proposed Pressure Recovery Study Options ................................................... 49 


\section{LIST OF SYMBOLS}

$\begin{array}{llll}\delta & = & \text { boundary layer height } \\ \delta_{1} & = & \text { displacement thickness } \\ \delta_{2} & = & \text { momentum thickness } \\ \Gamma & = & \text { circulation } \\ \eta & = & \text { efficiency factor } \\ \rho & = & \text { air density } \\ \omega & = & \text { cylinder rotational velocity } \\ a, b, c & = & \text { generic functions } \\ \mathrm{d} & = & \text { cylinder diameter } \\ L & = & \text { lift per unit span } \\ \mathrm{P}_{\mathrm{t}} & = & \text { total pressure } \\ \Delta \mathrm{P}_{\mathrm{t}} & = & \text { change in total pressure } \\ \mathrm{q} & = & \text { dynamic pressure } \\ \mathrm{r} & = & \text { cylinder radius } \\ \mathrm{V} & = & \text { local velocity } \\ \mathrm{V}_{\infty} & = & \text { freestream velocity } \\ \mathrm{V}_{\mathrm{E}} & = & \text { cylinder edge velocity } \\ & \end{array}$




\subsection{Introduction}

To ensure the proper handling and performance of road vehicles an accurate aerodynamic assessment must be obtained. The only way to accurately measure the force and moments affecting these qualities is in a controlled wind tunnel environment. However, a wind tunnel cannot exactly match the airflow around a road vehicle due mainly to the floor boundary layer. This area of low momentum flow is not present when considering the normal situation of a road vehicle moving through stationary air. It was once thought that the boundary layer influence was negligible as long as the displacement thickness was less than $10 \%$ of the vehicle ground clearance ${ }^{1}$. This opinion has since been reconsidered when testing showed a 3.7\% difference on lift and other parameters with decreasing displacement thickness below the $10 \%$ level, on full scale models with significant ground clearance ${ }^{2}$. This problem becomes even more critical when a model, or vehicle with very low ground clearance is tested. That is why techniques have been developed to minimize boundary layer effects for automotive testing. The way this is accomplished is by removing or reenergizing this area of low-momentum flow.

In this paper, the techniques commonly used for boundary layer control are compared. Highest consideration is given to cost and simplicity while still considering other important parameters such as flow quality. Then an alternative technique for boundary layer control is proposed that utilizes the spinning cylinder Magnus effect to energize the boundary layer. Two experiments were performed in order to characterize the applicability of this system. First a pilot study was conducted in the Boundary Layer Tunnel, followed by a full scale test in the Walter H. Beech Memorial Wind Tunnel. The final goal was to judge this concept's effectiveness and gain valuable design information. 


\subsection{Background}

The boundary layer thickness is defined as the height at which the local velocity, $\mathrm{V}$, is $99 \%$ of the incoming velocity, $\mathrm{V}_{\infty}$. Other parameters used to describe the boundary layer development along the wind tunnel floor are displacement thickness

$$
\delta_{1}=\int_{0}^{\infty}\left(1-\frac{\mathrm{V}}{\mathrm{V}_{\infty}}\right) d y
$$

and momentum thickness

$$
\delta_{2}=\int_{0}^{\infty} \frac{\mathrm{V}}{\mathrm{V}_{\infty}}\left(1-\frac{\mathrm{V}}{\mathrm{V}_{\infty}}\right) d y
$$

The magnitude of these parameters can be directly related to the amount of energy lost in the incoming flow due to viscous effects encountered at and near the wall.

There are many well known techniques used to solve the natural wind tunnel boundary layer problem, each with their own advantages and disadvantages. Figure 1, from $\mathrm{Hucho}^{3}$, illustrate the many possibilities that are available including:
a.) no correction
f.) ground offset
b.) reflection model
g.) distributed suction
c.) rolling road
h.) tangential blowing
d.) simple suction
i.) distributed blowing
e.) ground plane
j.) boundary layer fence.

A short comparison of some more commonly used techniques, and their places of application, was made as a first step in evaluating the merits of each system. 


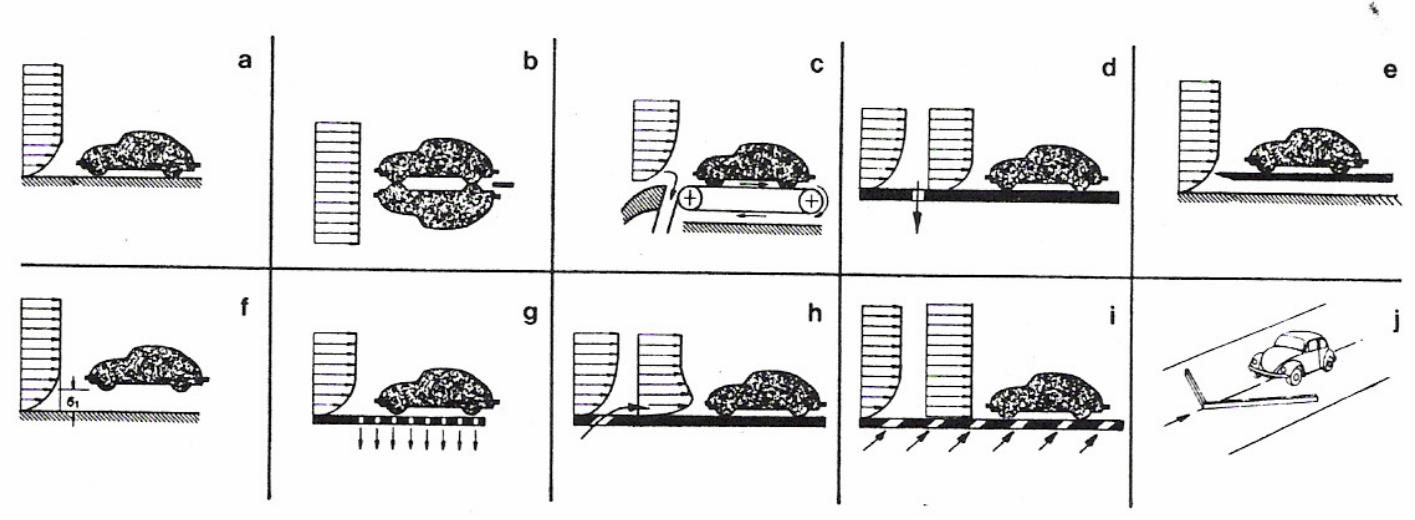

\section{Figure 1: Boundary Layer Control Techniques ${ }^{3}$}

\subsection{Rolling Road}

Of these techniques only the rolling road technique combined with initial suction can, in principle, match all the on road airflow properties. This technique is especially valuable in high performance road vehicle testing, such as in Formula 1 racing, where underbody design is crucial. In the MIRA Model Wind Tunnel the local air velocity in the test section remains within $\pm 1 \%$ free-stream velocity all the way down to the rolling belt surface ${ }^{4}$. In some cases it is even possible to incorporate the tire movement along with the body aerodynamics. In a less exotic implementation the rolling road does not span the entire test section width but still gives a very good flow representation.

However, this ability to match true flow quality comes at a hefty price. Implementing a rolling road system into a wind tunnel is a very costly and complex process. The equipment required to move the surface synchronously with the airflow is expensive to implement and even more so to maintain. Often it is also impossible to use an external balance so an internal balance system must be used. Furthermore, any tunnel not exclusively used for road vehicle testing would not want to install and remove the bulky equipment whenever it is not being used. Overall this technique is only feasible in 
an environment where cost is of no option and the flow must be modeled with absolute precision.

\section{$\underline{\text { 2.2 Suction Systems }}$}

Systems designed to "suck off" the boundary layer are widely used as alternatives to rolling roads. These systems come in a variety of implementations ${ }^{5-6}$ but they all have the same general principle: remove the boundary layer by sucking it through the floor and reintroduce the same volume flow downstream. Some systems apply suction at the test section entrance, resulting in a fresh new boundary layer developing behind the suction location. This boundary layer will be much smaller than without the suction, but it will still grow along the test section floor. In order to avoid this boundary layer the vehicle may need to be placed slightly off the floor even though this violates the geometric similarity slightly. Often this problem can be solved by using a distributed suction approach that continually removes the boundary layer throughout the perforated test section floor. Usually the suction velocity requirements for flush-mounted systems can require a significant amount of power. This can also be alleviated some by using an upstanding scoop to take advantage of the natural pressure gradient to assist the suction.

Suction systems provide a very viable alternative to the rolling road approach. However, the drawbacks to this type of system include a certain amount of power requirements for the suction and reintroducing the flow. Also required is a significant amount of space to duct the flow around the test section before reinsertion. While their implementation is much more affordable the flow quality does suffer. Since the object of

these systems is to remove a portion of the flow in the test section the use of such a system can produce unintended pressure gradients, flow angularities, and turbulence 
which can significantly affect the flow quality especially if the system is not properly tuned $^{7-8}$. Furthermore, if the flow is not re-introduced in the same amount as it was taken off then the conservation of mass is violated resulting in excess negative pressure in the test section. In this case extra tunnel venting is needed to relieve the pressure difference.

\section{$\underline{2.3 \text { Blowing Systems }}$}

Another widely used system type is the blowing approach. This approach relies on injecting high momentum flow from a narrow slot tangentially along the floor. It is the only method in which a profile can be generated where the velocity near the floor is greater than the freestream. This can be beneficial in that this allows some leeway in the uniform flow position placement. For example, if the blowing occurred at the test section entrance and the model was several feet back an overdeveloped profile could be generated so that the boundary layer growth would result in a nearly uniform profile at the model. This reduces the boundary layer growth problem dealt with in the suction cases.

While this technique is employed in several tunnels including the German-Dutch DNW Wind Tunnel and Lockheed's Low Speed Wind Tunnel in Marietta Georgia, it has its own drawbacks. First, the momentum is added in the form of a very thin jet of air that often needs to travel at greater than four times the freestream velocity 9 . Moving flow at that speed requires a significant amount of compressor power which can become expensive quickly. This can also create a very noisy environment in the test section. Furthermore, the introduction of this degree of momentum next to the floor distorts the velocity profile well above the floor. These flow angularity effects are an order of magnitude smaller than those encountered in suction systems ${ }^{9}$. 


\subsection{Other Techniques}

The most common system remaining is the ground board approach. In this method the vehicle is placed directly on an elevated platform. This platform creates its own new boundary layer that is normally much smaller than the tunnel's natural boundary layer. The implementation is very simple, easy to remove, and quite inexpensive in comparison to other techniques. The tunnel used in this work has the ground board as its main capability for road vehicle simulation.

Just as in suction the boundary layer is only new at the ground board front edge. When the ground board is put into the test section it creates a disturbance that causes the dynamic pressure in the test section to be different and often unknown. Also these ground boards, if not designed carefully, can have flow separation at their leading edge. This phenomenon was observed in NASA Langley's Full Scale Tunnel causing the boundary layer on the ground board to be greater than that on the test section floor ${ }^{10}$.

The other technique worth mentioning is the reflection plane model technique. Theoretically this technique, with proper post-processing, will give a true representation of a road vehicle without having to worry about the boundary layer altogether. By mounting two identical models symmetrically on the test section centerline the true ground similarity is reproduced.

The similarity technique is not used very often because the test requires two models so the cost of construction for the customer is doubled. This also forbids full scale testing since not very many tunnels in the world are capable of holding two vehicles. Since models must be used similarity to full scale is an added concern. With the current state of technology this technique is nearly obsolete. 
Often the best solutions to the problems encountered in boundary layer control involve using a combination of methods. For example most rolling roads have a suction system installed ahead of them to give a fresh boundary layer. Another interesting approach was used in the Daimler Chrysler Aero Acoustic Full Scale wind tunnel ${ }^{11}$. An upstanding scoop suction system was immediately connected to a tangential blowing system. Therefore as soon as the flow is removed from the floor it is immediately reintroduced in an energized state.

All of these techniques are well documented in their performance and some may be applicable in current focus on the Wichita State University 7'x10' wind tunnel. With recent upgrades ${ }^{12}$ it has become a highly advanced facility and the addition of a boundary layer control system would mean an increase in ground vehicle testing. Most of these techniques are, however, either too expensive or not sophisticated enough for the resolution available in the data gathered. The future goal of this work is to find an alternative that befits a tunnel of its sophistication with a cost appropriate to a university tunnel. 


\subsection{Proposed Boundary Layer Control Concept}

Since cost and simplicity is of greatest importance it is hard to justify using a more expensive method discussed above. Therefore, in order to obtain the improvement desired to attract more automotive testing, a study was performed to evaluate an alternative idea for boundary layer control.

In order to keep the design simple and space efficient there would be no ducting or complicated volume movement in the boundary layer. This also means keeping the power required to a minimum. The system must be as non-intrusive to the flow as possible to reduce angularity effects. Finally, the system must provide a significant momentum addition to the boundary layer. To meet these requirements the decision was made to consider a partially exposed rotating cylinder mounted in the test section floor to energize the boundary layer. Figure 2 is a sketch of the proposed concept.

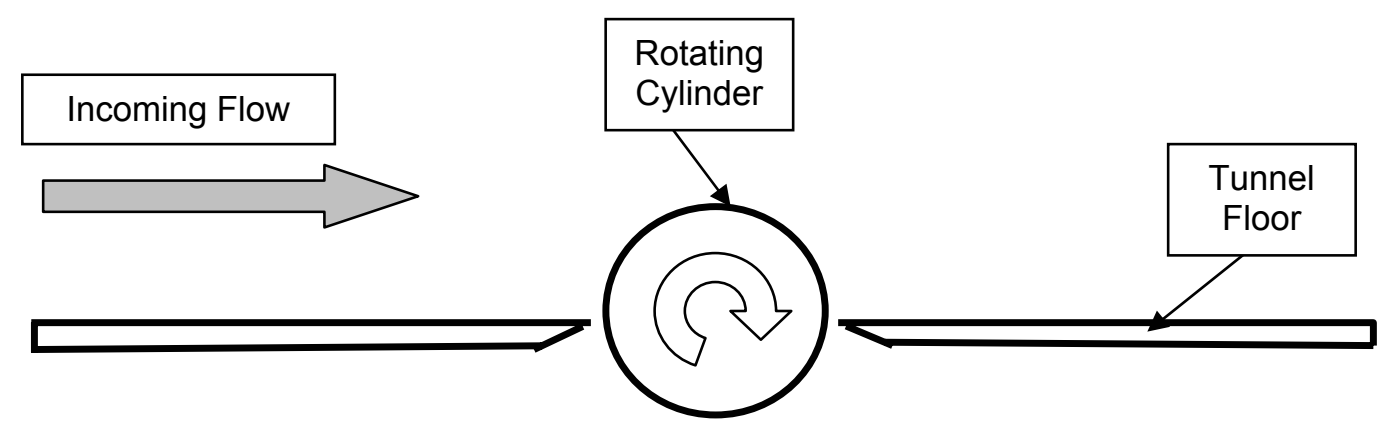

Figure 2: New Boundary Layer Control Concept Sketch

A rotating cylinder in uniform flow has been shown, in many experimental investigations, to create lift. This force is referred to as the Magnus force. The lift is generated by inducing a component of circulation, $\Gamma$, into the flow. This effect is also predicted in inviscid, potential flow, as the result of a vortex in a uniform flow. 
The Kutta-Joukowski theorem gives the following relationship between lift per unit span, L', and vortex strength, $\Gamma$ :

$$
L^{\prime}=\rho \cdot \mathrm{V}_{\infty} \cdot \Gamma \quad \text { or } \quad C_{L}=\frac{\rho \cdot \mathrm{V}_{\infty} \cdot \Gamma}{\mathrm{q} \cdot \mathrm{d}}
$$

For the case of a cylinder we will assume:

$$
\Gamma=\oint \mathrm{V} \cdot d s=\eta \cdot \int_{0}^{2 \pi} \mathrm{V} \cdot \mathrm{r} \cdot d \theta=\eta \cdot 2 \pi \cdot \omega \cdot \mathrm{r}^{2}
$$

Where $\eta$ represents nonlinear effects caused by viscous interactions.

The cylinder lift is not what is most important in these two equations. Instead the induced velocity profile from the rotating cylinder is the main concern of this analysis. The goal of boundary layer control is to create a uniform velocity profile. Figure 3 shows if we consider vector addition of an oversimplified boundary layer velocity profile with the profile created by a potential vortex the result is that of a uniform profile.

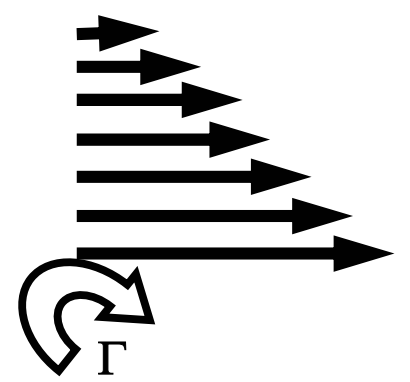

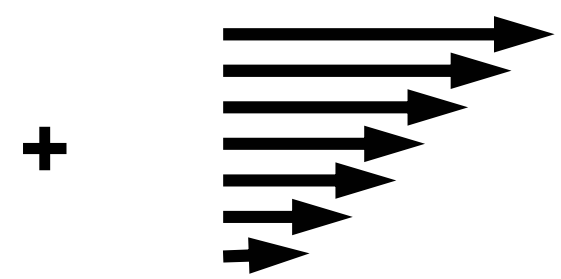

BL Profile

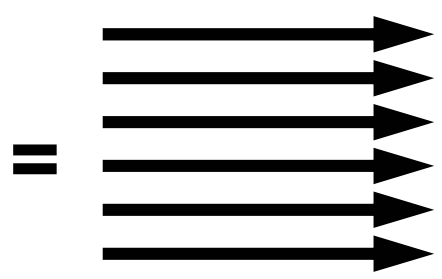

Uniform Profile

Figure 3: Velocity Profile Manipulation

While potential flow theory describes the physics well qualitatively, there are viscous effects that must be considered. Since these effects are difficult to estimate the efficiency factor, $\eta$, is applied to Equation (4) using data from Hoerner ${ }^{12}$ in Figure 4. 


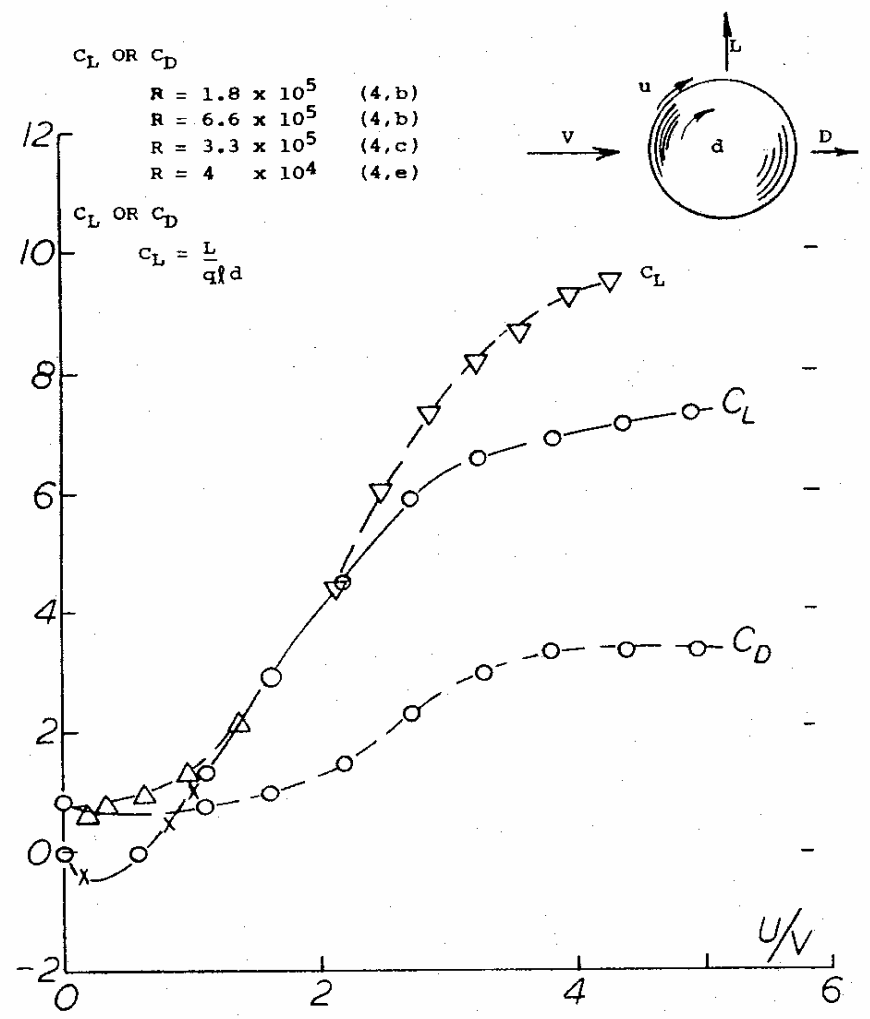

Figure 4: Lift Generated by a Rotating Cylinder in Uniform Flow ${ }^{12}$

Since these data were experimentally collected the viscous effects are included in the values obtained. The quantities plotted in Figure 4 are lift coefficient with respect to the cylinder's diameter, $C_{L}$, versus the cylinder velocity relative to the incoming flow, U/V (equivalent to the author's $\mathrm{V}_{\mathrm{E}} / \mathrm{V}_{\infty}$ ). What is most interesting in this survey are the circulation, $\Gamma$, and rotational velocity, $\omega$. Through simple algebraic manipulation of Equations (3) and (4) these values are extracted and plotted in Figure 5. 


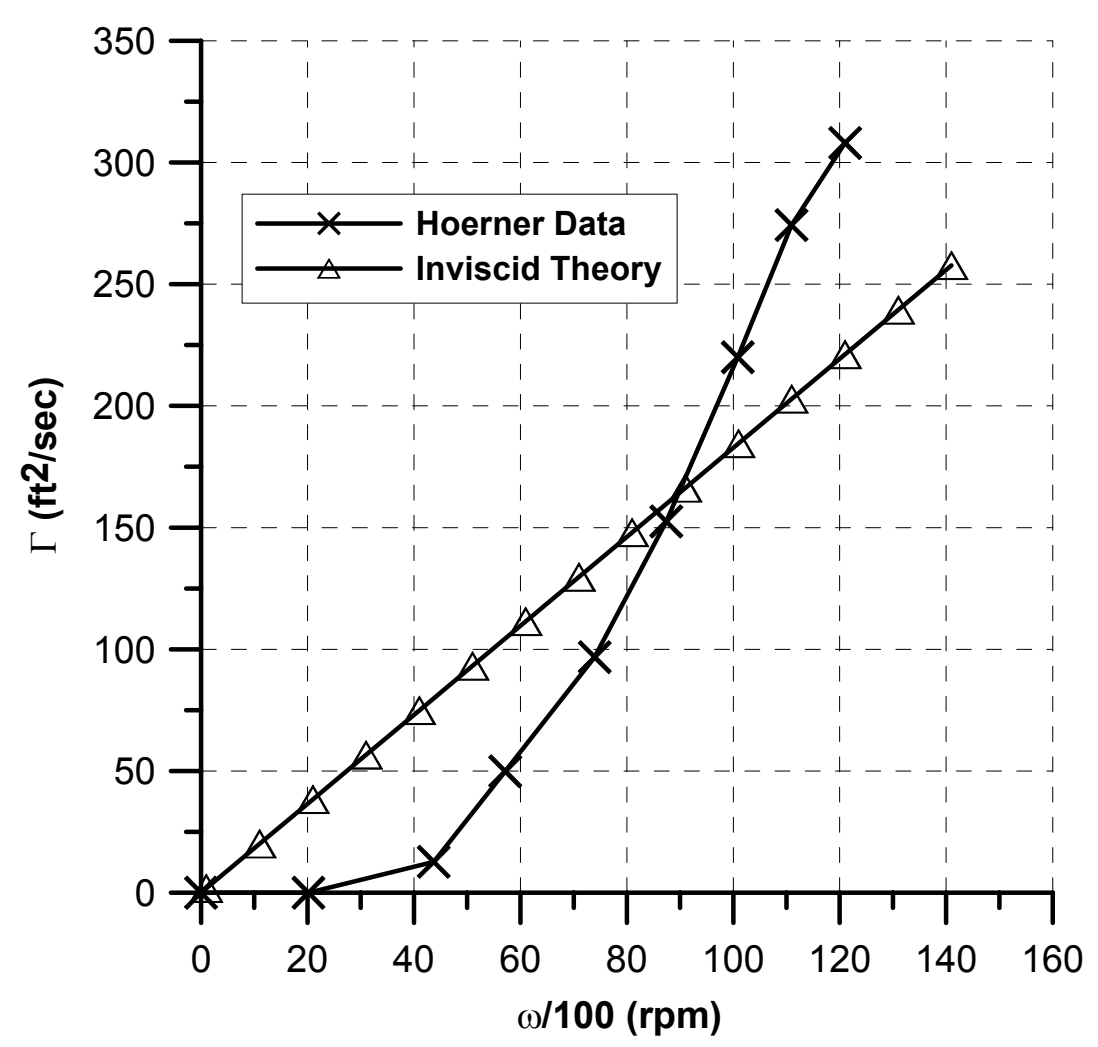

\section{Figure 5: Comparison of Potential and Experimental Circulation Values vs. Rotational Velocity}

From Figure 5 it is evident that the linear theory over-predicts the circulation in the lower range and under-predicts it at the higher speeds. This plot was done for a fully exposed cylinder of radius 2 inches. By increasing the radius size, higher values of circulation can be obtained at lower rotational velocities and the intersection of these two curves occurs at a much lower rotational speed. Obviously there are limits on the size of cylinder that can be used, the amount of exposed arc, and the maximum rotational velocity attainable. Sensitivity studies were used to try to quantify these effects for design implications.

For the time being the interesting assessment of Figure 5 is the difference in the curves' shapes. The curve-fit equations show the theory to be linear and the experimental values follow a quadratic profile, as might be expected. This means the efficiency factor, 
$\eta$, will be a function of rotational velocity and cylinder radius, not a constant value. The form of which is,

$$
\eta=a \omega+b+c \omega^{-1}
$$

where $\mathrm{a}$ and $\mathrm{c}$ are functions of cylinder radius $\mathrm{r}(\mathrm{ft})$, and $\mathrm{b}$ is simply a constant. They are defined as:

$$
\mathrm{a}=7.5606 \times 10^{-5 * \mathrm{r}} \quad \mathrm{b}=0.372 \quad \mathrm{c}=135.46 * \mathrm{r}^{-1}
$$

This equation can be reduced to a single variable by applying the equation for $\omega$ in terms of $V_{E}$, as shown in Equation (6),

$$
\omega=\frac{60 \cdot \mathrm{V}_{\mathrm{E}}}{2 \pi \cdot \mathrm{r}} \quad(\mathrm{ft} / \mathrm{sec})
$$

and back substituting $\omega, \mathrm{a}, \mathrm{b}$, and c into (5) we get the single variable form in Equation 7.

$$
\eta=0.0007220 \cdot \mathrm{V}_{\mathrm{E}}-0.372-14.185 \cdot \mathrm{V}_{\mathrm{E}}^{-1}
$$

Now using Equation (4) including the correction factor, $\eta$, we can solve for corrected circulation, $\Gamma_{\text {corr }}$ In turn using $\Gamma_{\text {corr }}$ in Equation (4) will give the true rotational velocity needed to reach the desired circulation.

So what circulation is needed to fill the momentum lost in the boundary layer? Since the boundary layer shape is defined by its velocity profile it seems logical to consider the streamwise velocity profile generated by the rotating cylinder added to the incoming boundary layer. As a first approximation we will consider the velocity initially equal to $\mathrm{V}_{\mathrm{E}}$ and decrease linearly away from the tunnel floor. This approximation does not take into account the exposed cylinder height or vertical component of velocity lost at the wall. So by adding the initial velocity profile to the profile generated by circulation from the rotating cylinder we can see the reduction in boundary layer thickness. 


\subsection{Experimental Boundary Layer Measurements}

During this research two separate experiments were conducted in order to gather information about this concept. The first experiment took measurements in the Boundary Layer Tunnel as a quick and easy first test of the theory. From the favorable results obtained, a second test was conducted in the Walter H. Beech Memorial Wind Tunel (BMWT) using a more sophisticated setup. The methodology of each experiment is further detailed in this section.

\subsection{Boundary Layer Tunnel Pilot Study}

First a pilot test was performed in order to determine whether or not this concept was feasible and what kind of problems might be encountered. It was a way to test the proposed system's effectiveness in order to decide whether a full scale test was warranted.

The facility utilized in this pilot study is the Boundary Layer Tunnel. This facility, shown in Figure 6, is an induction type tunnel driven by a variable speed centrifugal fan in an open atmosphere environment. It is equipped with an inclined manometer board as a check to the portable Scanivalve system used to record pressure information in this test. The Scanivalve was controlled through a Visual Basic algorithm in an Excel spreadsheet, written by Monal P. Merchant, a current M.S.A.E. student at WSU. The tunnel is approximately $13.5 \mathrm{ft}$ long with a 14 in. X $6 \mathrm{in}$. X 36in. test section. It is driven by a 22in. diameter, centrifugal fan with a coarse mesh of rectangular flow straighteners. The inlet has a 3.75:1 contraction ratio and the reference length from inlet to test section is $8.0 \mathrm{ft}$. 


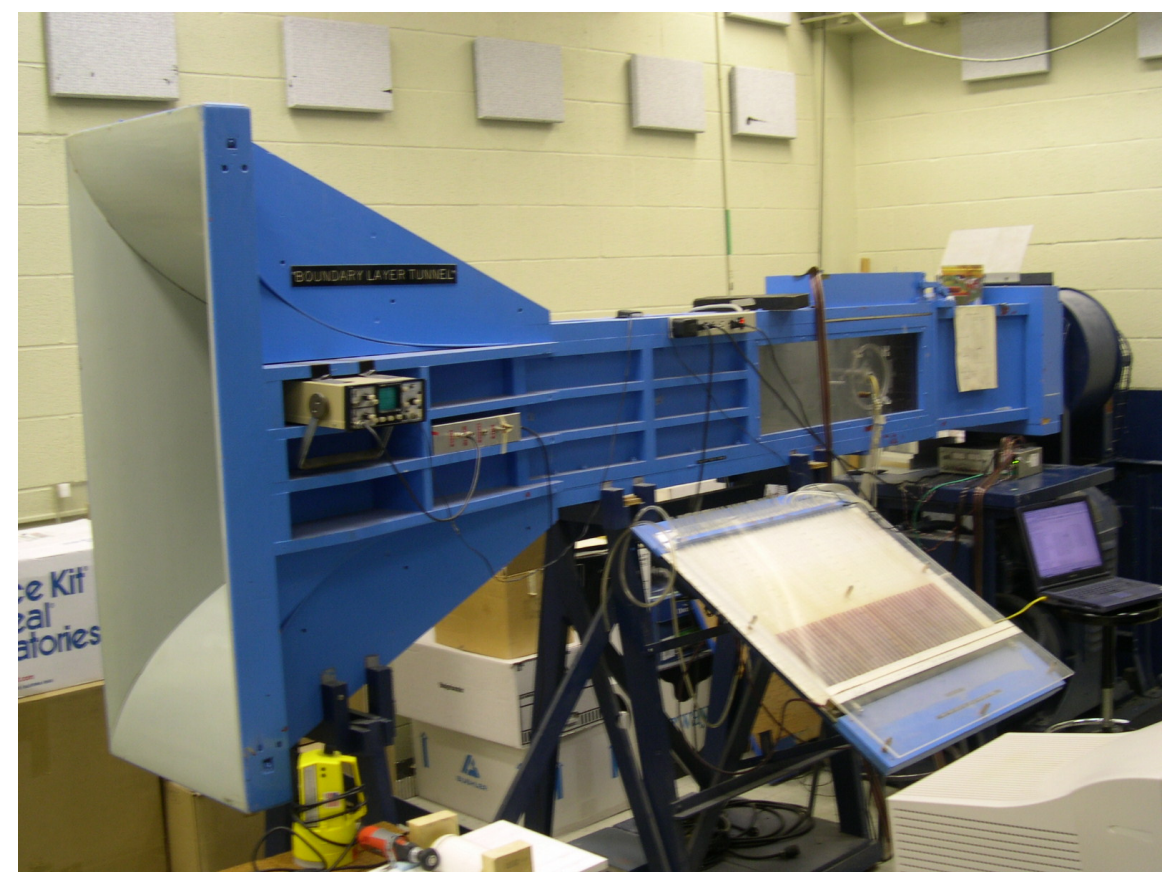

Figure 6: Boundary Layer Tunnel

First, a baseline survey was conducted for three different velocities in order to characterize the boundary layer in the test section. The Boundary Layer Tunnel has a hinged test section ceiling where measurements were taken. A trip was used in the inlet region in an attempt to force a turbulent profile. The profiles were nearly the same for each speed so no further effort was put into adjusting the trips. A quick calculation shows the average Reynolds Number for the tunnel at full speed is $6.0 \times 10^{5}$ per foot. For comparison purposes the profile for the Boundary Layer Tunnel is plotted along with the BMWT profile in Figure 9.

The experimental setup used to test the rotating cylinder effect on the boundary layer consisted of a laminated shelf with a 6in. piece of 3.5in. outside diameter PVC pipe. A slot with beveled edges was cut through the shelf and the cylinder was mounted using model aircraft tires fixed inside the pipe with a steel axle running through their center. The axle was attached to wooden blocks with bearings mounted inside them to allow free 
rotation. The cylinder was driven by a rotary tool with another small model aircraft wheel attached to the rotary mount. Rotational velocities were recorded using a stroboscope. Figure 7 shows an exterior view of the setup described. Also added, but not pictured were brushes, made from simple paint brush bristles, to reduce the venting from the test section into the open room.

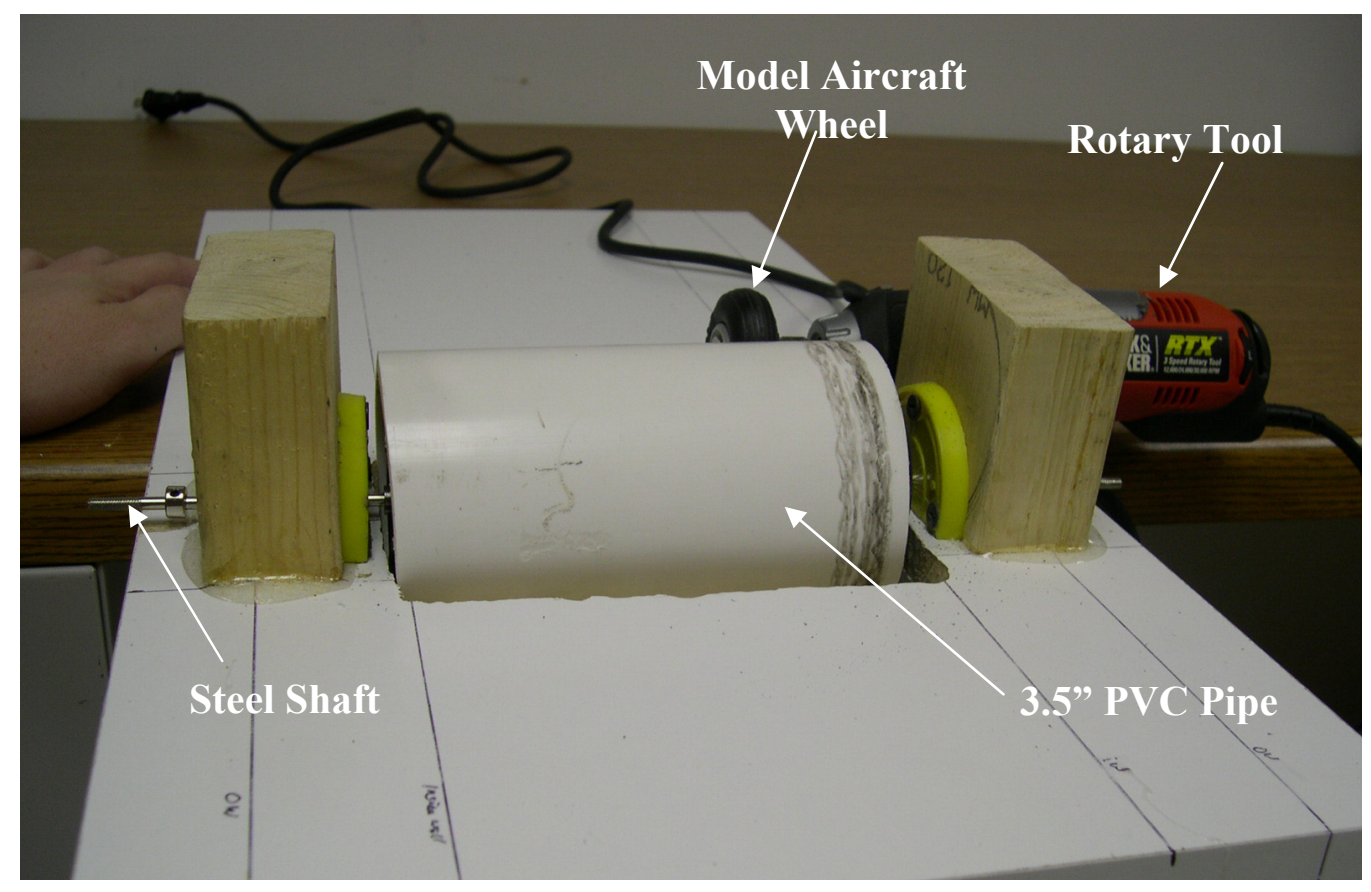

Figure 7: Experimental Boundary Layer Control Setup

Boundary layer profiles were recorded at the tunnel maximum velocity of approximately $65 \mathrm{mph}$ for three different cylinder rotational velocities: $\mathrm{V}_{\mathrm{E}}=0,4100$, \& 6500rpm. The successful results from this simple experiment, presented in section 5.1, would provide a case for the feasibility of this method. Unfortunately, further tests could not be conducted in the Boundary Layer tunnel due to a still unknown phenomenon occurring with the scanivalve equipment, after being borrowed by an undergraduate class, which caused readings to be erratic and unrepeatable in later testing. Although this limited testing the results, presented in this paper, were repeatable in the early tests. 


\subsection{BMWT Experiments}

After analyzing the results from the pilot study in the Boundary Layer Tunnel a more comprehensive test was conducted in the Walter H. Beech Memorial Wind Tunnel (BMWT). The baseline profiles obtained in the test section survey were repeated at the centerline location where it was most advantageous to insert the test cylinder apparatus in the removable part of the test section floor. From there a more comprehensive test matrix was conceived and carried out. The results of which are presented in section 5.2.

The BMWT facility itself was the main motivation for conducting this survey in order to attract more automotive customers. The tunnel is located on the Wichita State University Campus, in the National Institute for Aviation Research (NIAR). It was recently remodeled to include a more powerful and efficient $2500 \mathrm{Hp}$ drive system as well as a new heat-exchanger and honeycomb flow straighteners. It is a closed-loop, low speed wind tunnel, characterized by a $7 \mathrm{ft}$ by $10 \mathrm{ft}$ test section. The layout of this facility is illustrated in Figure 8.

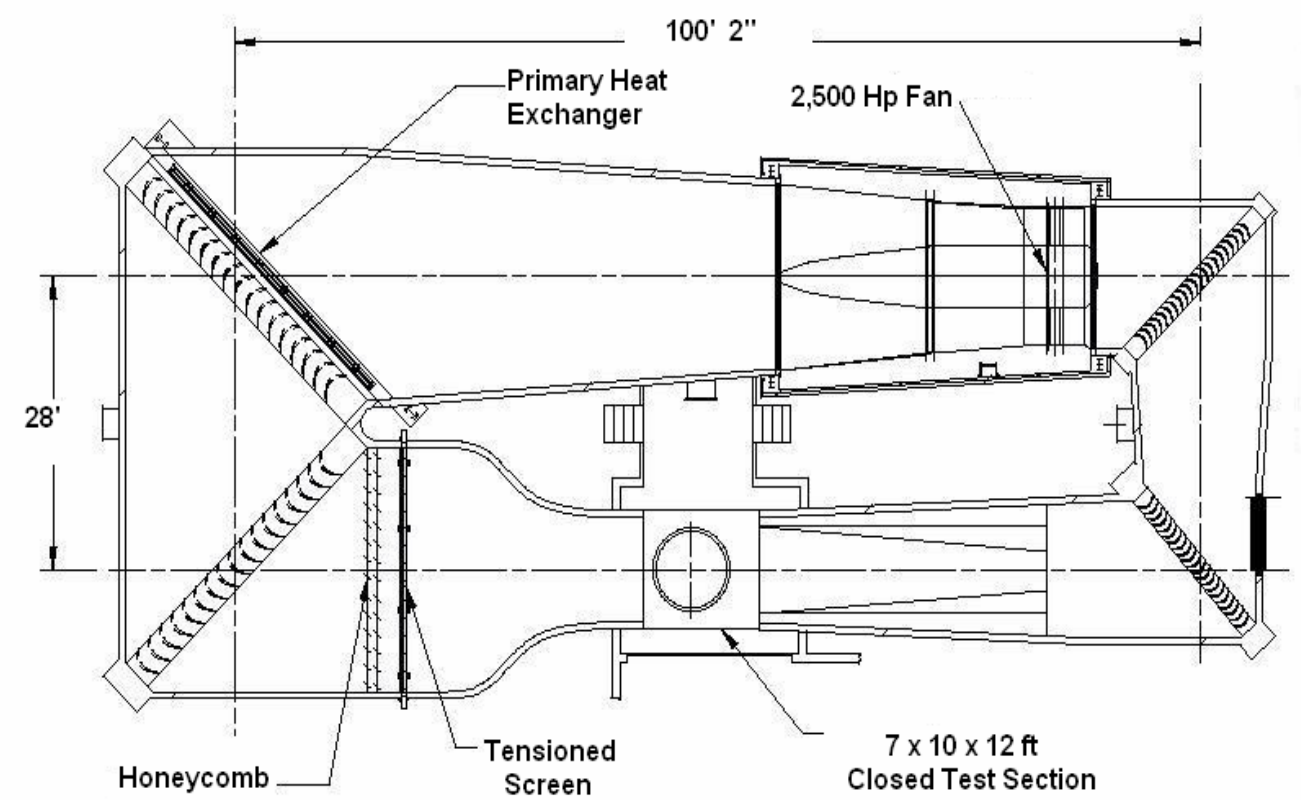

Figure 8: Walter H. Beech Memorial Wind Tunnel (BMWT) Diagram ${ }^{13}$ 
After the upgrade, the tunnel's flow quality had to be documented, including a boundary layer survey. The survey test matrix consisted of nine different locations and eight velocities at each location. Velocity profiles were recorded using a boundary layer mouse with 15 pitot static readings over a height of two inches connected to a PSI8400 pressure module. The survey results are included in Appendix A.

A new, slightly more sophisticated, boundary layer control apparatus was constructed by the author. This apparatus used a cylinder obtained from a previous project ${ }^{14}$ made from a rolled aluminum tube, $6.5 \mathrm{in}$. in diameter, $49 \mathrm{in}$. long and balanced on a steel rod $0.75 \mathrm{in}$. in diameter and 59in. long. The cylinder was free to rotate on bearings around the center rod. A frame constructed of $2 \times 4 \mathrm{~s}$ and $0.25 \mathrm{in}$. mahogany plywood was used to encase the cylinder for installation into the tunnel. The plywood had a slot $6.5 \mathrm{in}$. wide cut in it to allow the cylinder to pass through without touching at its most exposed position. A technique of adding brushes, used in limiting cross-flow between gaps in high lift devices of aircraft, was also implemented. These brushes were installed in the gap between the cylinder and surrounding frame to reduce cross-flow from the balance room into the test section. The drive system for the cylinder was a 3.5 Hp router motor mounted to one side and set below the cylinder. The electric motor could be adjusted on the fly using a variable-AC power controller. It was connected to the cylinder using a pre-tensioned automotive belt. This approach, however, made adjusting the height of the cylinder a major task. This setup, shown in Figure 9, could be dropped directly into the removable part of the test section floor. Furthermore, some tests required sandpaper on the cylinder which was applied using quick cure epoxy. Finally, the cylinder rotational velocity was recorded using a magnetic pickup device that output 
values of changing voltage in hertz to a Fluke multimeter which could then be converted to RPM or non-dimensional velocity values.
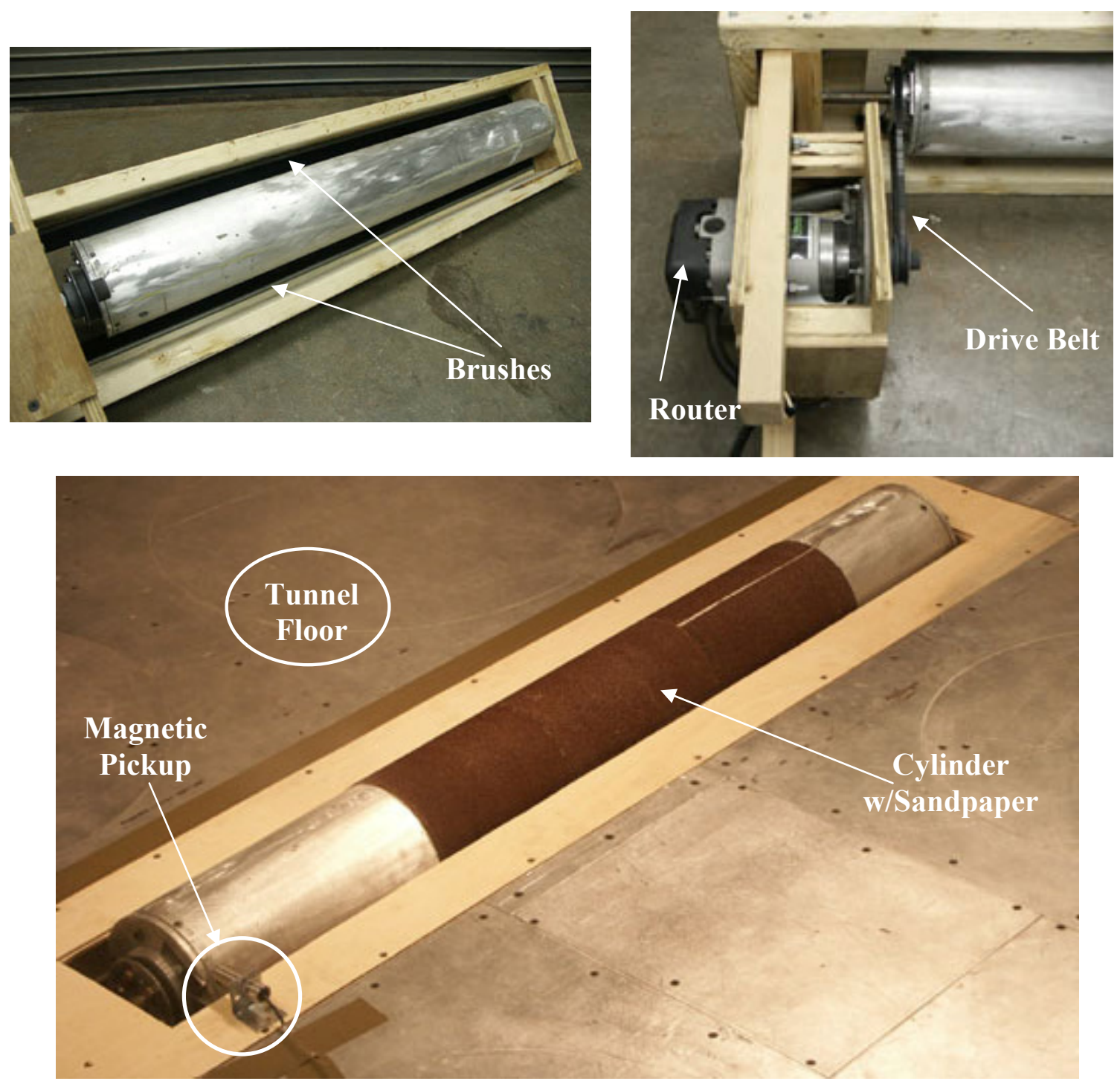

Figure 9: BMWT Experimental Apparatus

The test matrix used to collect data initially varied four major sensitivity parameters until a fifth, discovered during testing, was also added. These five parameters and the values tested are summarized in Table 1. 


\begin{tabular}{|l|c|}
\hline \multicolumn{1}{|c|}{ Sensitivity Parameters } & Values \\
\hline Tunnel Velocity, $\mathrm{V}_{\infty}(\mathrm{mph})$ & $40,60,80,100$ \\
\hline Cylinder rotational velocity, $\mathrm{V}_{\mathrm{E}}(\mathrm{rpm})$ & $1000,1500,2000,3000,4000$ \\
\hline Roughness & Smooth, 40grit Sandpaper \\
\hline Exposed height, $\mathrm{h}$ (inches) & $2.25,1.25,0.3$ \\
\hline Brushes & With, Without \\
\hline
\end{tabular}

\section{Table 1: BMWT Test Matrix}

Data from these tests was gathered in a similar way as in the Boundary Layer Tunnel, using the 15 pitot probe boundary layer rake. However, because of problems encountered with the Scanivalve, which forced the experiments to be cut short in the first test, the PSI- 8400 pressure system of the BMWT was used instead. Tests required two people to run; one controlling the speed of the cylinder using the variable-AC and a second taking data and running the tunnel from the wind tunnel control room. All data was recorded into a single comma-separated-variable (CSV) file and could easily be transferred to Microsoft Excel for reduction.

The final types of tests performed in the BMWT were flow visualization tests. These tests were conducted before each cylinder exposed height run to ensure the proper placement so three-dimensional effects were not affecting boundary layer rake data. They were then repeated to gauge the effect of the cylinder height on possible boundary layer separation. The data gathered from these tests was digital video recorded to DVD. 


\subsection{Results}

The results obtained from the tests in both the Boundary Layer Tunnel and the Walter H. Beech Memorial Wind Tunnel, described in section 4.0, are presented in sections 5.1 and 5.2 respectively. Section 5.3 will address some of the uncertainty values in the data and how those uncertainties were obtained.

\subsection{Boundary Layer Tunnel Results}

After characterizing the baseline boundary layer the experimental setup shown in Figure 7 replaced the ceiling, allowing the bottom section of the cylinder to be exposed to the incoming flow. Measurements were then taken for the tunnel maximum velocity setting with the cylinder at rest and spinning on the low and subsequently medium velocity settings of the rotary tool, corresponding to $4100 \mathrm{rpm}$ and $6500 \mathrm{rpm}$ respectively. The high velocity setting was attempted, but the unbalance present in the cylinder as well as the model aircraft wheel caused a failure in the drive wheel. The boundary layer rake was placed a distance of 3 inches behind the rotating cylinder in the initial run. From the results, plotted in Figure 10, a calculation of Equation (2) using trapezoidal integration showed the profile with the non-rotating cylinder has a $\delta_{2}$ value $250 \%$ of the baseline

case. Again, the baseline case consists of boundary layer data that was taken in an empty test section without the cylinder apparatus installed. 


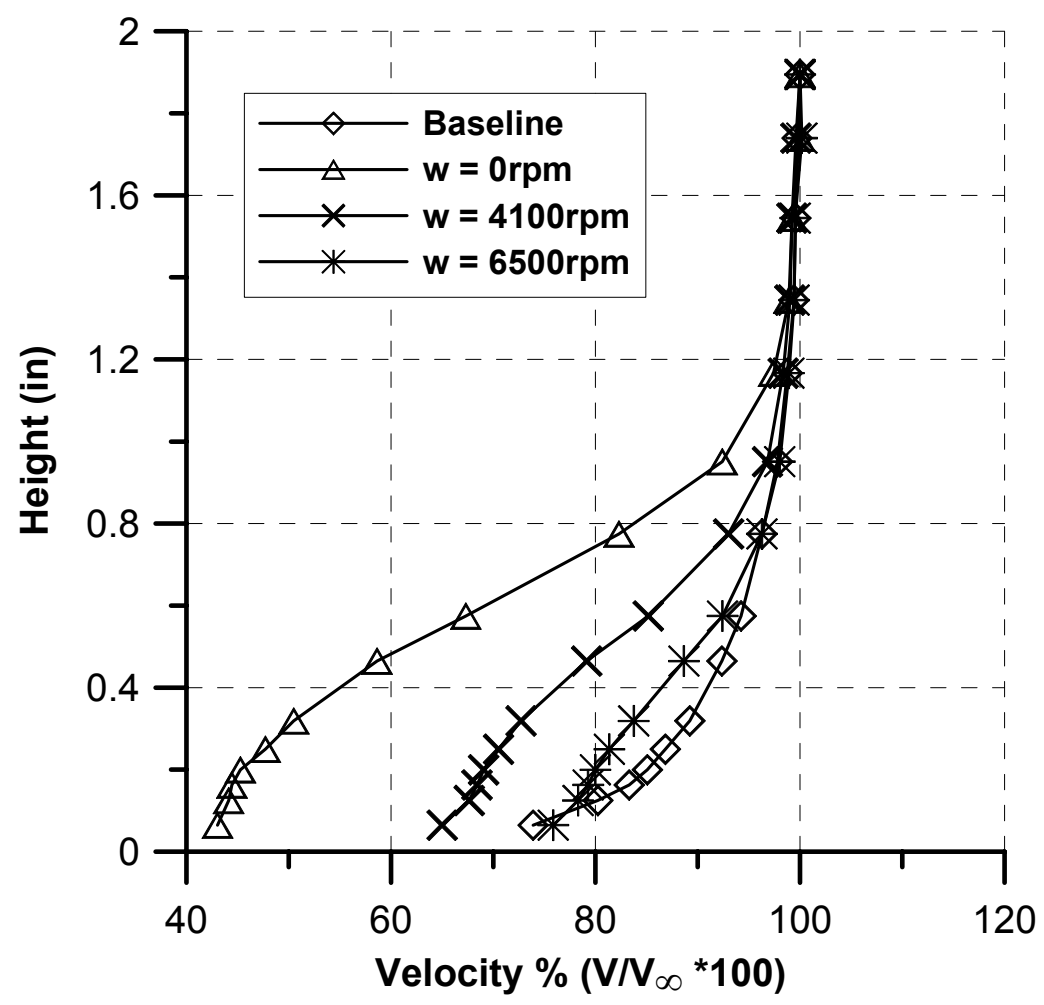

Figure 10: Initial Cylinder Test Results

From this plot we can see the stationary cylinder significantly increased the size of the boundary layer momentum and displacement thicknesses from the baseline profile. It was thought the boundary layer rake was simply too close to record an accurate measurement. However, it is apparent the rotating cylinder does energize the boundary layer and change the profile. From the initial still velocity to the 4500rpm and 6500rpm rotational velocities there is a large difference in the area under the curve, which equates to the momentum displacement thickness. Another observation shows the $\delta_{2}$ value for the $6500 \mathrm{rpm}$ case is only $116 \%$ of the baseline.

A second test was done with the boundary layer mouse mounted 11 inches behind the cylinder, at the test section exit. The test was repeated and the results are plotted in Figure 11. 


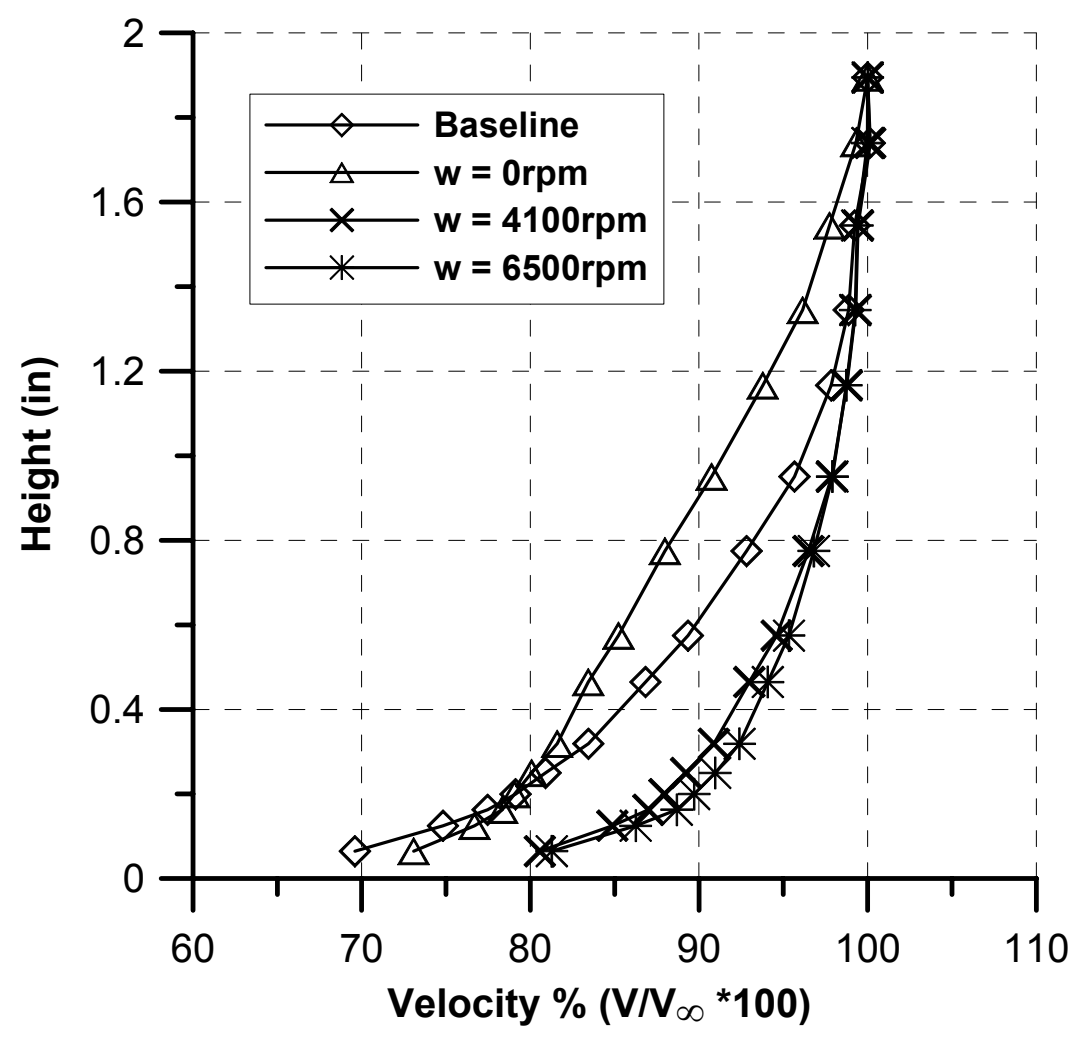

Figure 11: Second Cylinder Test Results

The second test results indicated the cylinder rotating at $4100 \mathrm{rpm}$ and $6500 \mathrm{rpm}$ could actually reduce the boundary layer momentum thickness to $59.7 \%$ and $54.6 \%$ of the baseline profile, respectively. It was also evident that the cylinder's affect on the measurements was greatly reduced to where the profile with the non-rotating cylinder and the baseline profile were much more similar in shape. While the limited speed range of the current rotary tool allowed only two rotational velocities, Figure 12 illustrates the level of improvement achieved in direct momentum thickness reduction. 


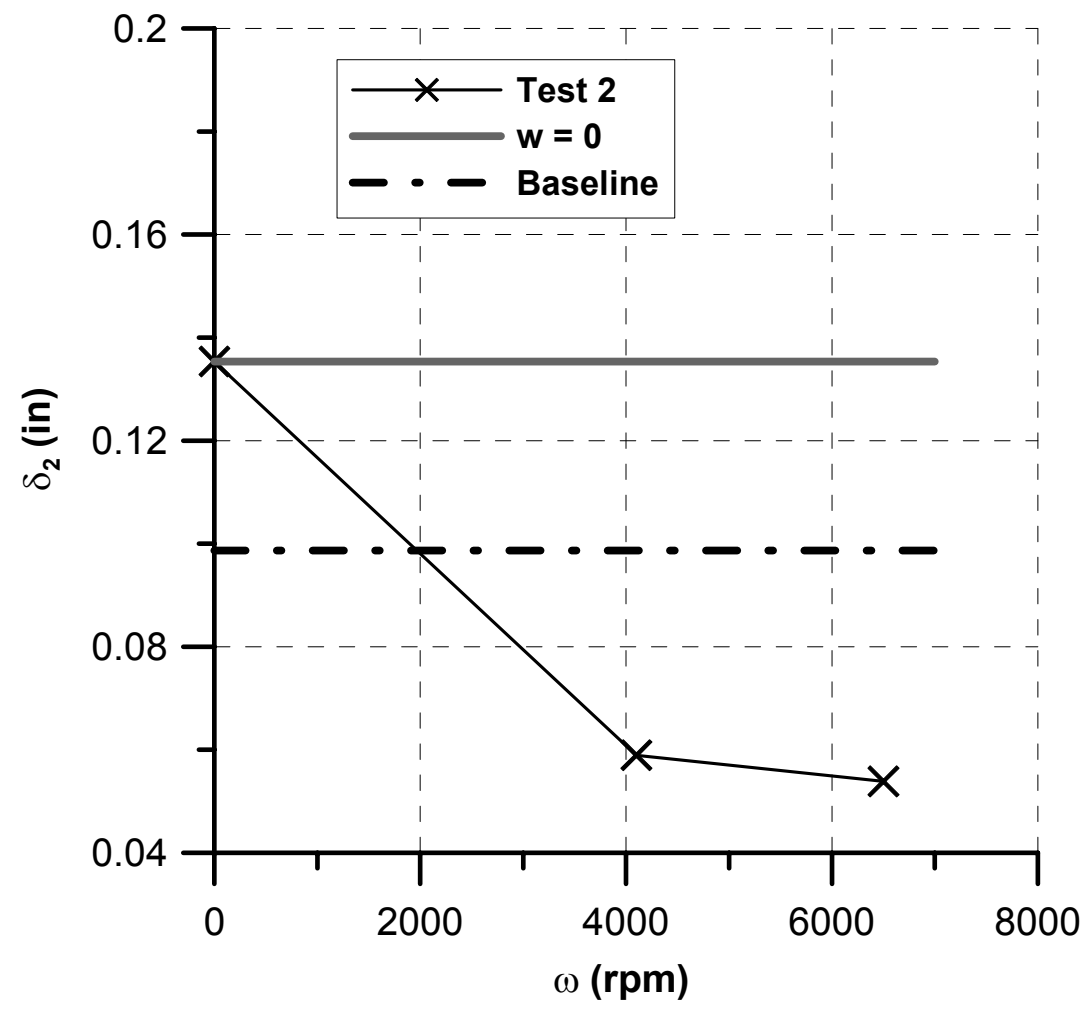

Figure 12: Momentum Thickness Reduction vs. Rotational Velocity, $\omega$

These pilot test results seem to indicate the method discussed can be successful in application as well as theory. At this point the decision was made that a test in the BMWT could yield some important results regarding sensitivity analysis and feasibility of full scale implementation.

\subsection{BMWT Test Results}

Results from the BMWT boundary layer survey showed the boundary layer thickness varied from approximately 1 inch at the inlet to above 3 inches at the test section exit. Since our experiment occurred at the centerline location an average profile for that location is shown in Figure 13. 


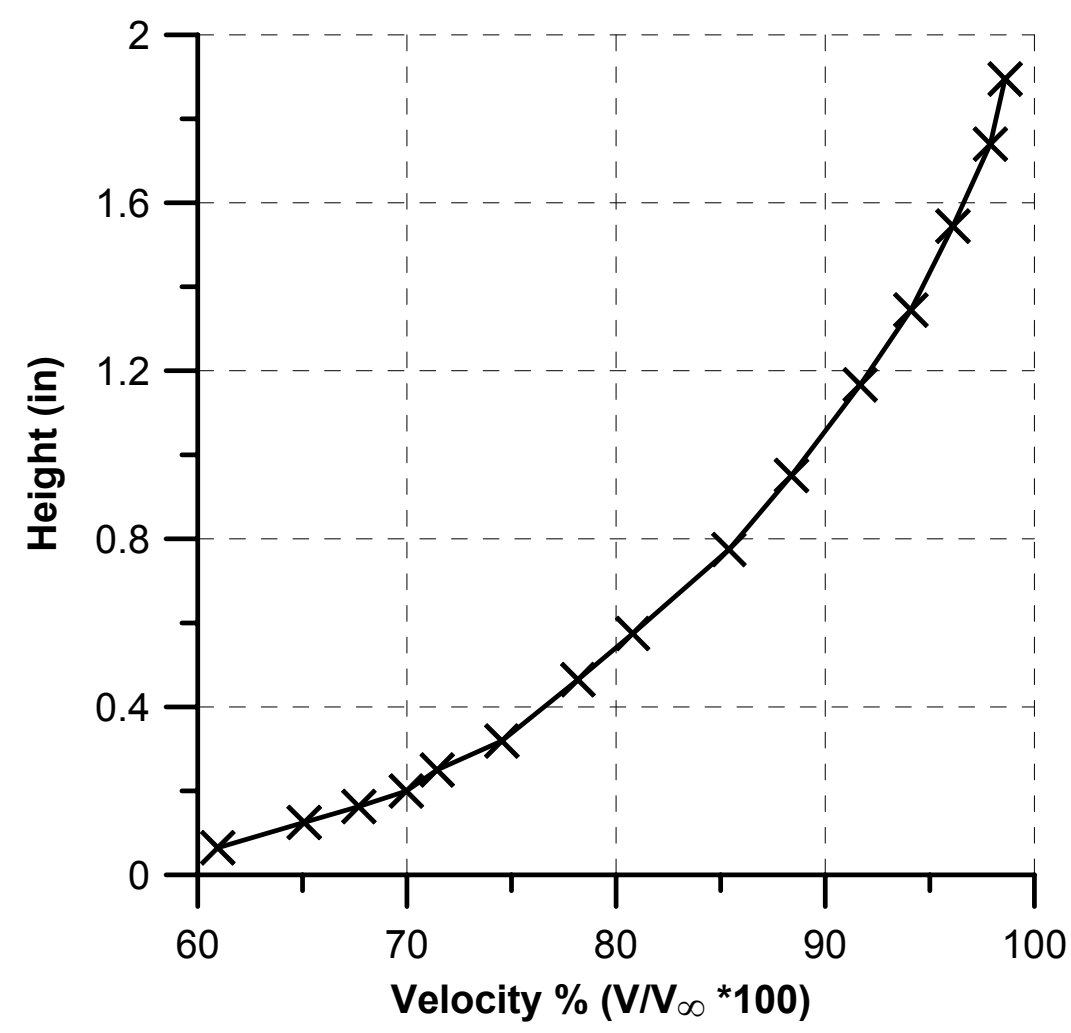

Figure 13: BMWT Nominal Boundary Layer Profile

This is the baseline profile for the BMWT test. The baseline momentum thickness obtained from trapezoidal integration of this profile was $0.1445 \mathrm{in}$. If we compare this profile shape to that of the Boundary Layer Tunnel, as in Figure 14, it is clear the two experiments are attempting to solve two different problems. The two profiles were not expected to match, but it is interesting to note the difference in shape. During the Boundary Layer Tunnel test the possibility of a laminar profile was feared, however if we make the reasonable assumption that the BMWT shape is consistent with that of a turbulent profile we can reasonably assume with the shape similarities between the two profiles, seen in Figure 14, the Boundary Layer Tunnel profile was also turbulent. This means that, although the magnitudes of momentum thickness will be different, the behavior will not be subject to laminar separation problems. 


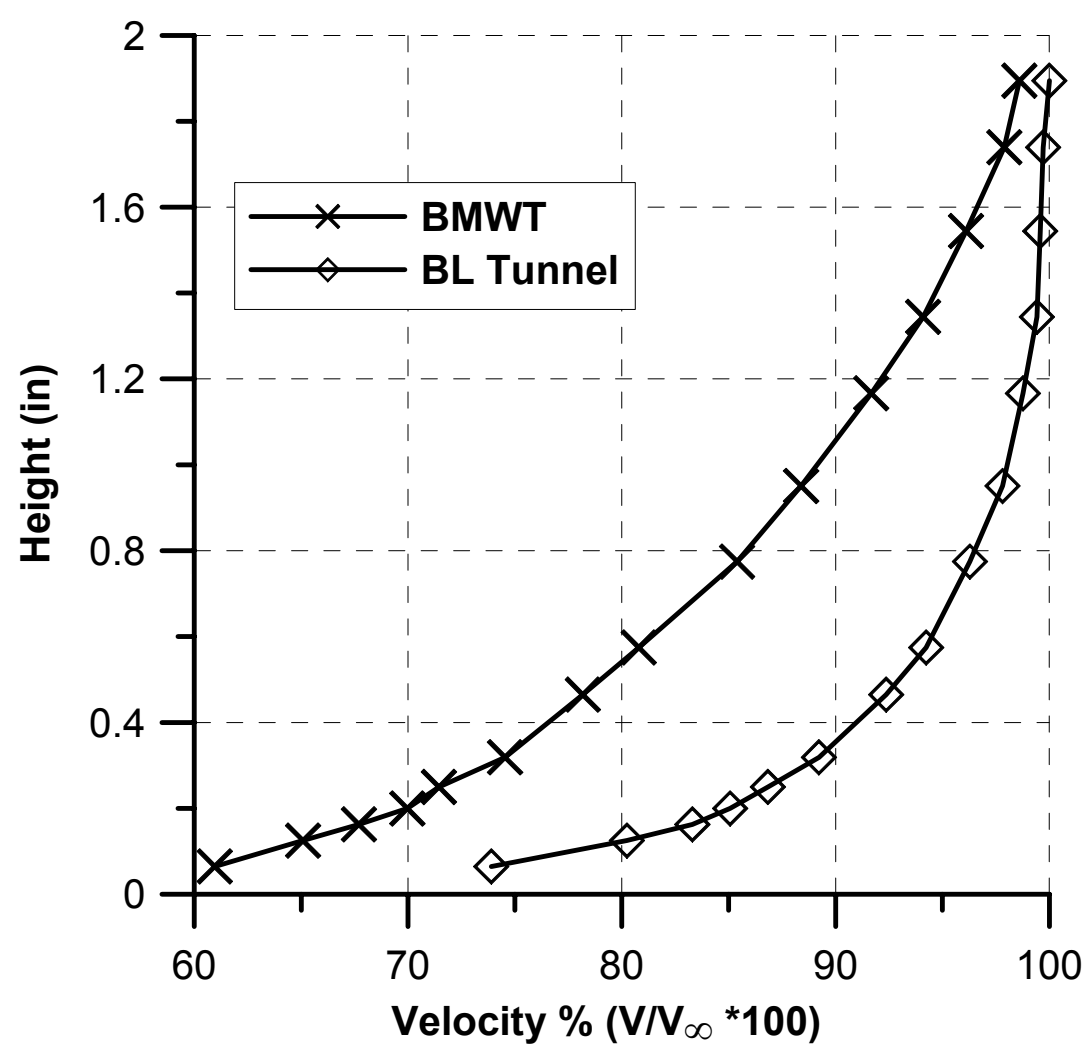

Figure 14: Boundary Layer Profile Comparison

Now that we can be reasonably confident the two tests will behave in much the same way, tests including the cylinder can be performed.

\subsubsection{Tunnel Velocity Sensitivity Results}

The inner loop of the overall test matrix was the tunnel velocity, $\mathrm{V}_{\infty}$. This parameter was the easiest to change, requiring only an input from the tunnel operator and time to stabilize resulting in less than 2 minute transition times. The purpose of testing this variable was to confirm the consistency of the boundary layer shape as well as note the variation in initial momentum thickness with respect to $\mathrm{V}_{\infty}$. Figure 15 shows just how the shape differs for different tunnel velocities, with the main difference being the growth in momentum thickness for each higher velocity. 


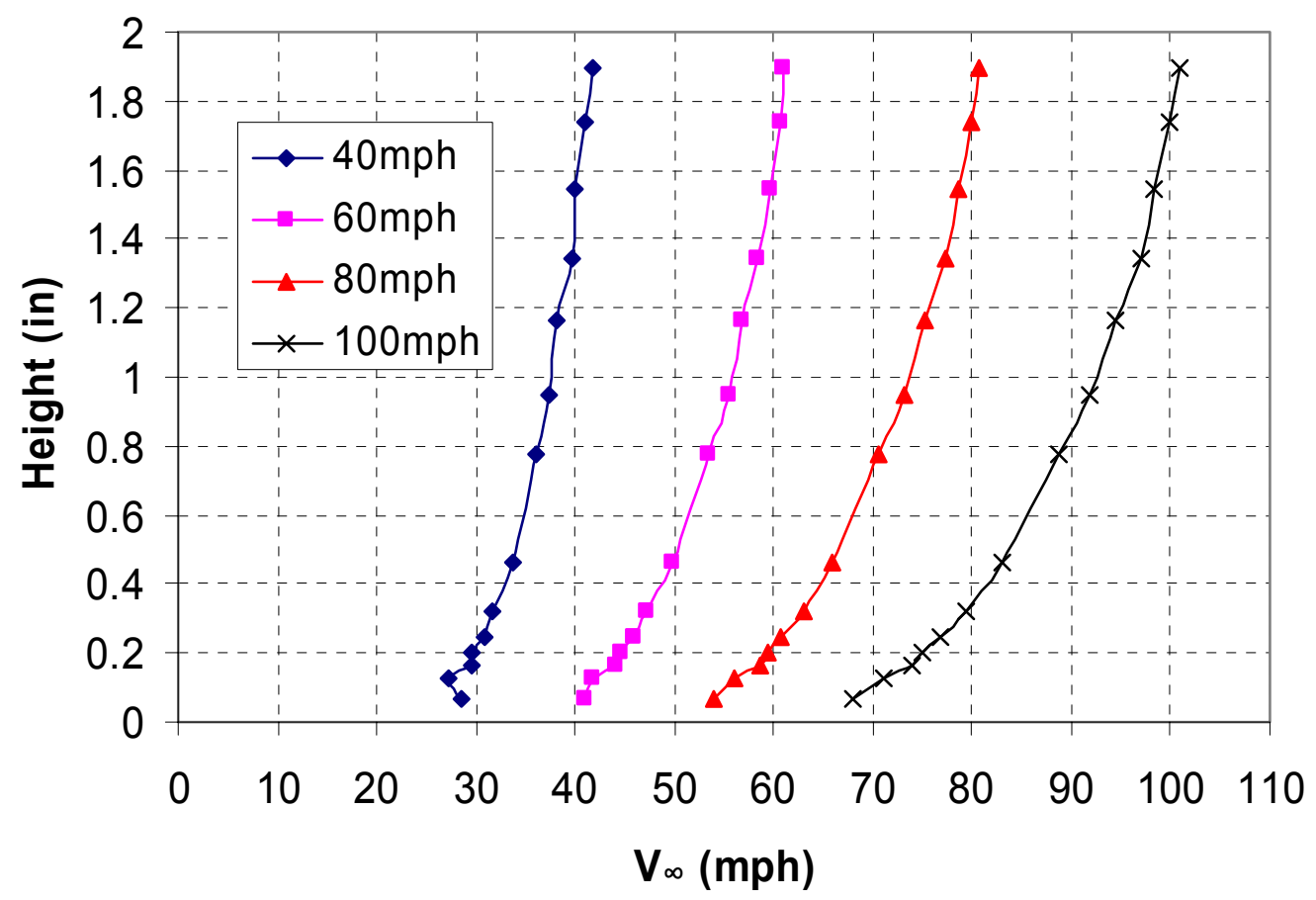

Figure 15: Boundary Layer Profiles of Different $V_{\infty}$

If we non-dimensionalize the velocity into a percent of the tunnel velocity, $\left(\mathrm{V} / \mathrm{V}_{\infty} * 100\right)$ notice in Figure 16 how conveniently the profiles collapse on one another.

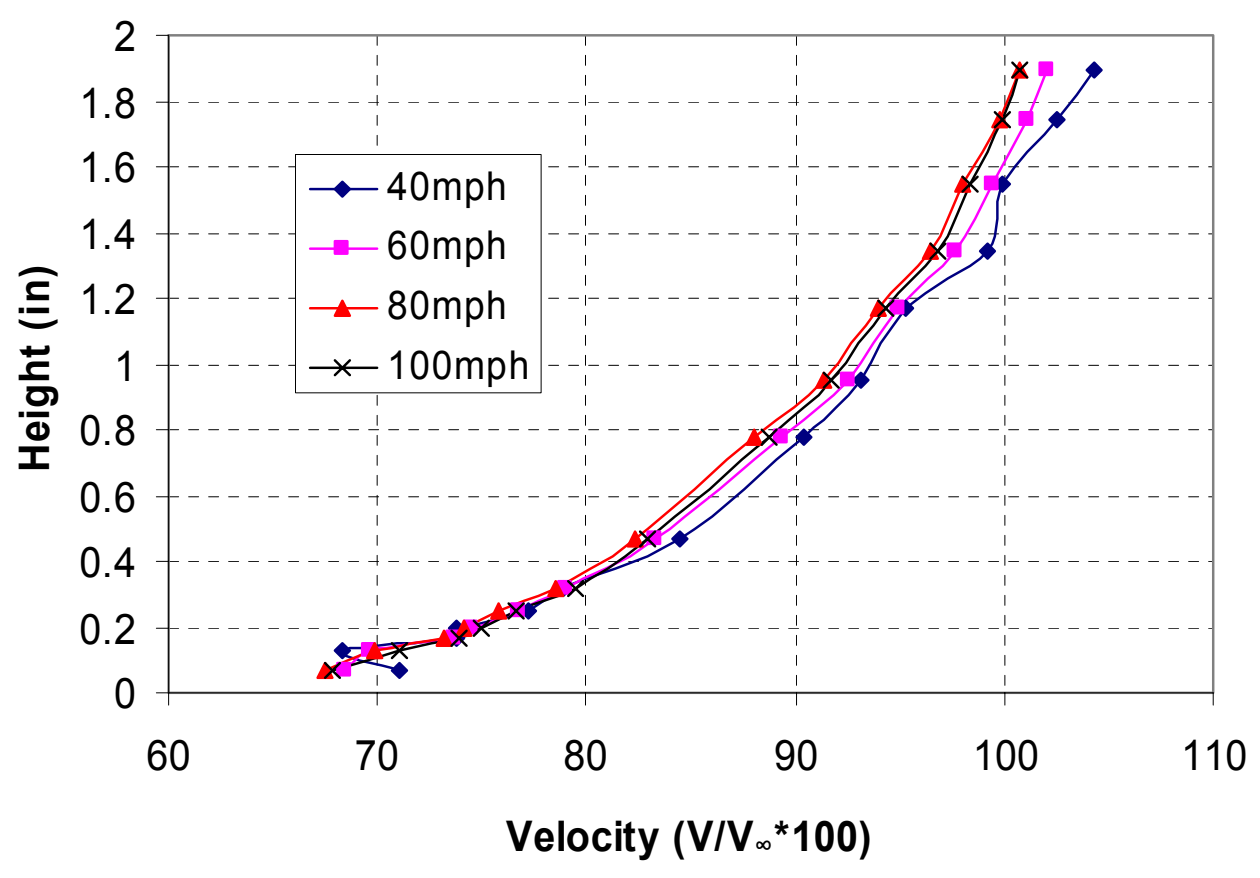

Figure 16: Non-Dimensional Boundary Layer Profiles of Different $V_{\infty}$ 
Another observation from these plots shows the $40 \mathrm{mph}$ plots to be generally less well-behaved. Further scrutiny reveals the Reynolds number for the $40 \mathrm{mph}$ case is $3.3 \times 10^{5}$ per foot, well below the general guideline of $5.0 \times 10^{5}$ for fully turbulent flow. This ill-behavior proceeded through all calculated values and was considered unreliable. The remaining three values of $\mathrm{V}_{\infty}$ had reasonable Reynolds number values. Therefore, the $40 \mathrm{mph}$ case will be omitted in the remainder of the findings. Also for the remainder of this paper, variables that are independent of $\mathrm{V}_{\infty}$ will be demonstrated using only the $60 \mathrm{mph}$ case for simplicity.

\subsubsection{Rotational Velocity Sensitivity}

The next parameter of great importance in reducing the momentum thickness using this technique is the rotational velocity of the cylinder. This parameter will be represented in either its dimensional form, $\omega(\mathrm{rpm})$, or the edge velocity, $\mathrm{V}_{\mathrm{E}}$, nondimensionalized by the tunnel velocity, $\mathrm{V}_{\mathrm{E}} / \mathrm{V}_{\infty}$. For both experiments, this was the main variable of interest during testing.

The rotational velocity settings, $\omega$, used during testing were; 1100rpm, 1500rpm, 2000rpm, 2775rpm, 3100rpm, and 3900rpm respectively. Not all tests used all six rotational velocities and the unevenly spaced $\omega$ values reflect the problem of the cylinder imbalance problem. This resulted in locations of harmonic vibrations, which were avoided if at all possible. The maximum rotational velocity was limited by this vibration phenomenon as well, but this author contends that a professionally fabricated setup could spin at much higher $V_{E}$ values.

The first results presented in Figure 17 are the rotational velocity effects on the total pressure profiles. Total pressure was used instead of velocity as a better description 
of the energy present in the flow and because we did not have a good static pressure measurement, reliable velocities could not be obtained.

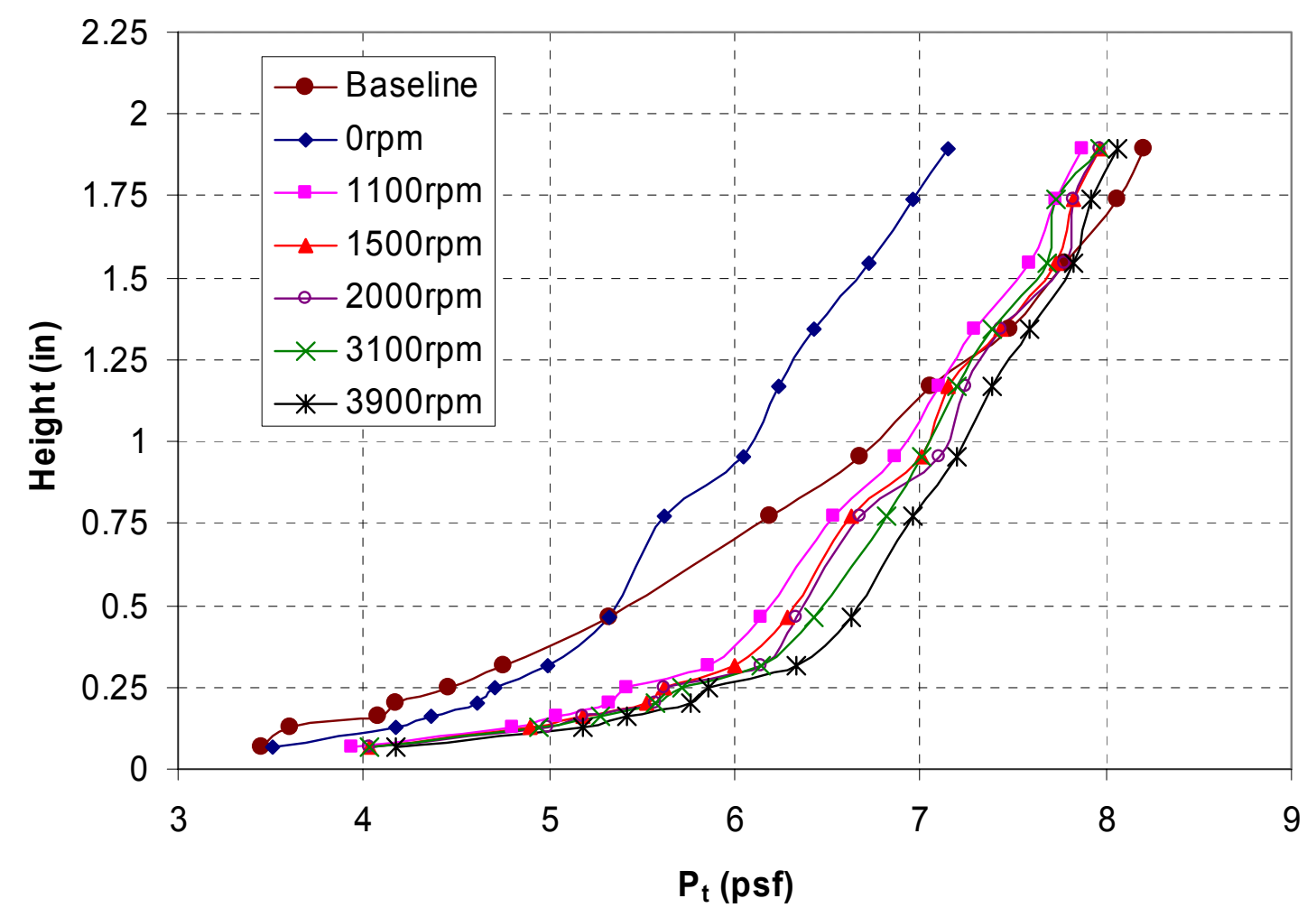

Figure 17: Total Pressure Profiles for Different $\omega$ Values

The first observation made from this plot is that the profile for $\omega=0$ is significantly worse that the baseline (no cylinder) profile. The same was true in the Boundary Layer Tunnel test. Secondly, as the rotational velocity increases the profile fattens and is slightly shifted to the right. This is exactly the predicted effect that is needed to reduce the momentum and therefore displacement thicknesses. The last observation worth noting in this profile is the slight misalignment of the profiles at the top port location. If one were to extrapolate these curves it would be more apparent the displacement thickness has been increased slightly. This also means the boundary layer 
rake is now completely below the boundary layer, and undesirable effect but not crucial. All the major trends are visible.

It is important to see how the cylinder rotational velocity effect performed compared to the theory. The induced velocity profile discussed in Section 3.0 can be extracted from the final data and is presented in Figure 18 in the form of a total pressure profile. This plot represents the total pressure value differences between a uniform velocity profile and boundary layer profile $\left(\Delta \mathrm{P}_{\mathrm{t}}=\mathrm{P}_{\mathrm{t} \infty}-\mathrm{P}_{\mathrm{tBL}}\right)$.

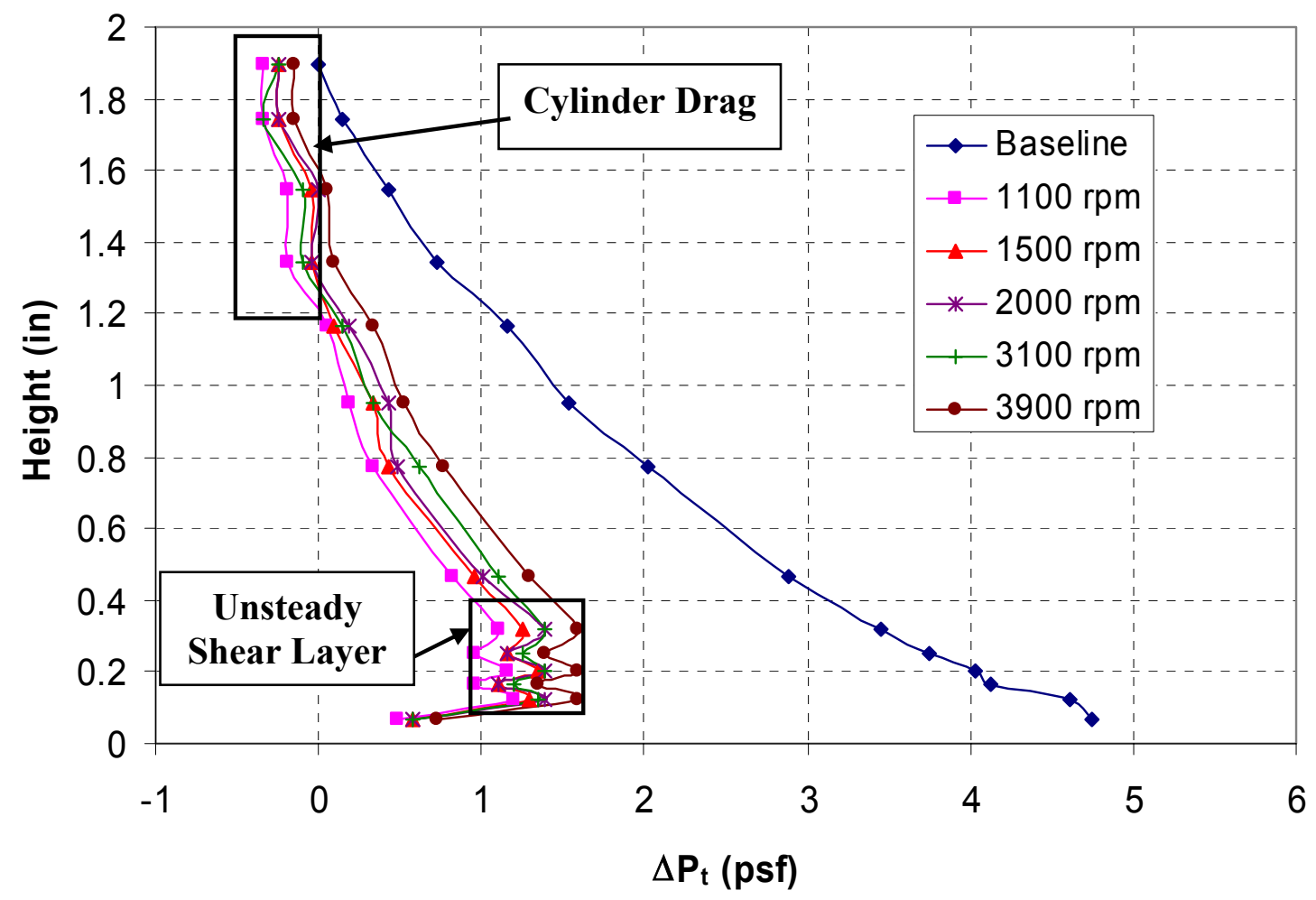

Figure 18: Induced $P_{t}$ Profiles for Different $\omega$ Values

It is apparent the rotational velocities tested are not sufficient to create a completely uniform profile, but that was not the goal. The velocities do seem a little below expectations with even the $\omega=3900 \mathrm{rpm}$ case producing barely $45 \%$ of the necessary induced profile for the uniform profile case. Another observation made from 
this plot is the negative values of $\Delta \mathrm{P}_{\mathrm{t}}$ present in the rotational profiles near the top of the boundary layer rake. Since negative values of $\Delta \mathrm{P}_{\mathrm{t}}$ can only be induced by removing energy from the flow, this effect is most likely the result of separation drag induced by the cylinder in the flow. In the normal case of a cylinder in the flow, theory suggests the flow should separate just past the $90^{\circ}$ arc location. This location should move aft as the cylinder is spun, but separation still occurs nonetheless. In the case of roughness added, this location moves forward, which is important to remember for Section 5.2.3. A look at the lower section of the profile reveals some apparent unsteadiness in the flow. This is most likely not caused by separation, since flow visualization runs showed no unusual separation near the probe. However, it is possible the flow is having difficulty settling behind the cylinder. Since the velocity vector of the cylinder is pointing downward into the aft floor there may be some unsteadiness caused by the abrupt redirection of the flow. Finally, the bottom two values in the profile seem to indicate a trend more like a normal profile. Since the boundary layer rake is a significant distance behind the cylinder it is possible these two values represent the shear layer growing along the floor, where the effects from the above unsteadiness are not felt. These irregularities are interesting but still not completely understood.

Figure 19 shows the direct effect of the cylinder rotational velocity on the nondimensional momentum thickness $\left(\delta_{2} / \delta_{2}\right.$ baseline $)$ for three different tunnel velocities $(60$, 80 , and $100 \mathrm{mph}$ ). The values were obtained using trapezoidal integration to solve Equation 2. 


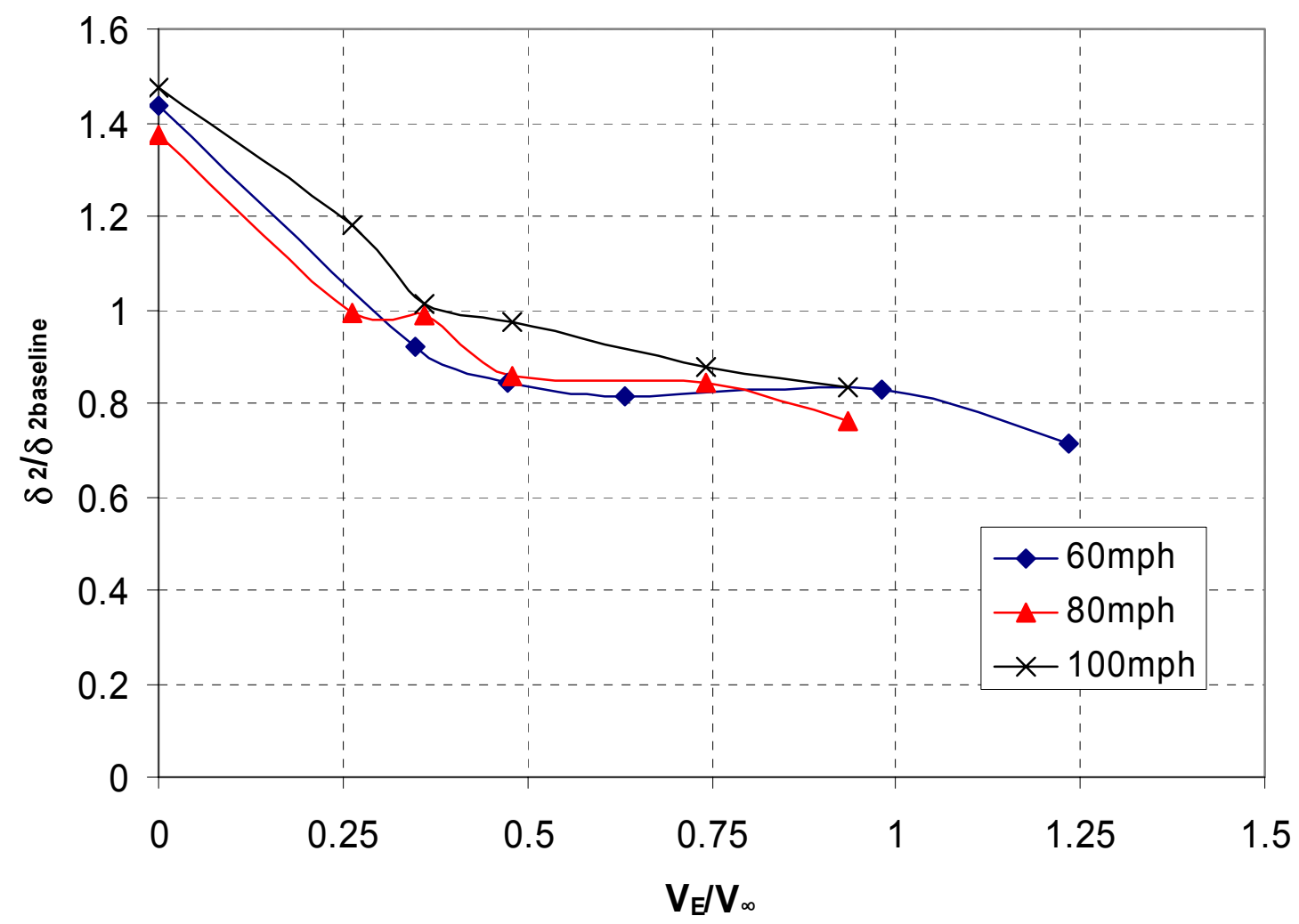

Figure 19: Momentum Thickness vs $V_{E} / V_{\infty}$

This plot shows for $\mathrm{V}_{\mathrm{E}} / \mathrm{V}_{\infty}=0$ the values are between 1.35 and 1.45 times greater than the baseline profile. This profile reduces to maximum reduction of $29 \%$ below the baseline profile, for the $60 \mathrm{mph}$ case. Improvement for the other velocities was slightly less, mainly because they are also at lower values of $\mathrm{V}_{\mathrm{E}} / \mathrm{V}_{\infty}$. The overall reduction in this momentum thickness varies by a third order polynomial. While each value of $\mathrm{V}_{\infty}$ had a slightly different trend, they all seem to condense into the same general band of values. Not only that, but the negative slopes of the profiles seem to extend past the collected data range. Therefore a better setup could provide a much improved system.

During the literature survey, some of the results quoted were in terms of displacement thickness. In this analysis, $\delta_{1}$ was not the main parameter used to gauge the results, but its values are presented in Figure 20 for completeness. 


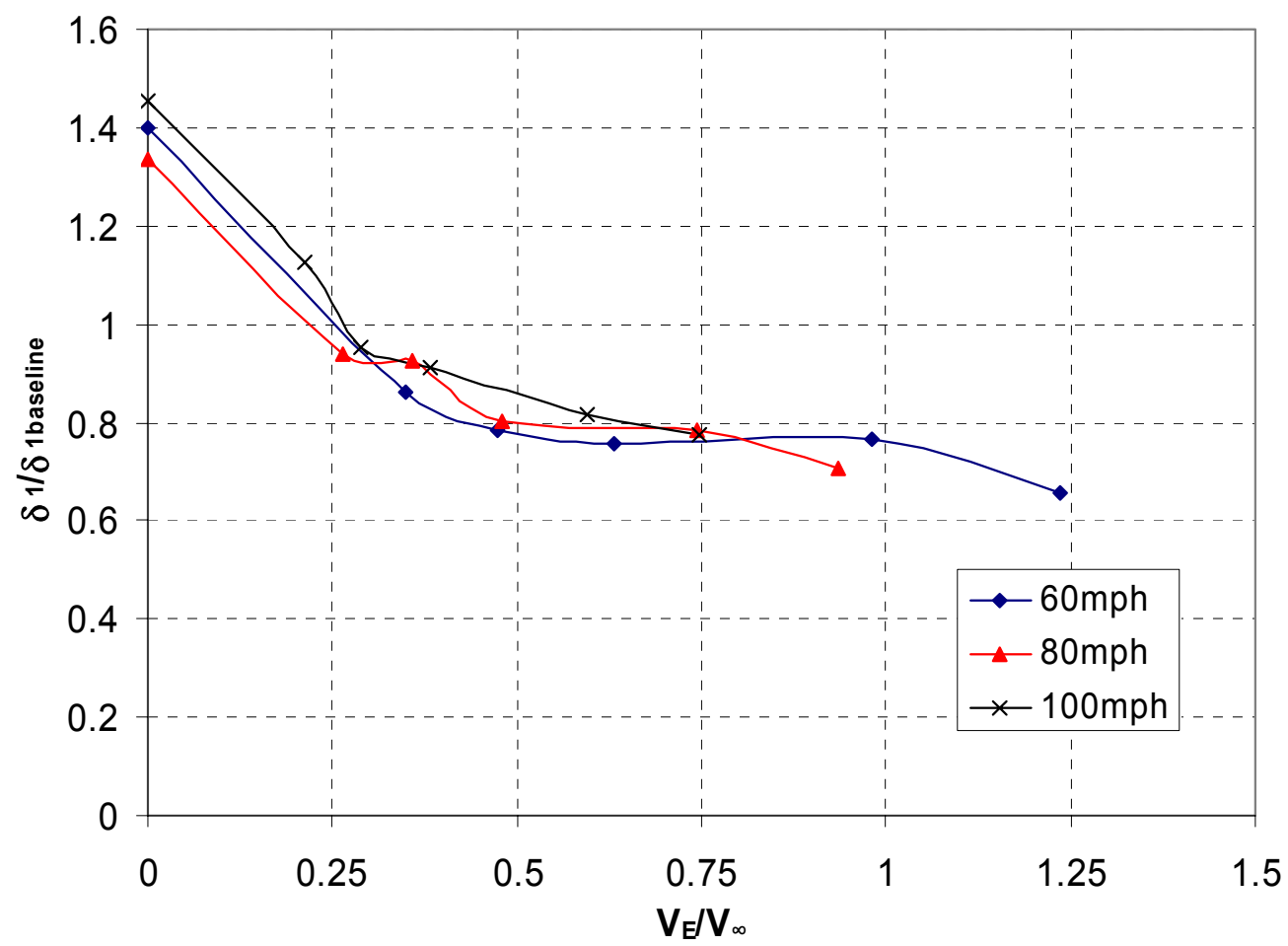

Figure 20: Displacement Thickness vs $\mathrm{V}_{\mathrm{E}} / \mathrm{V}_{\infty}$

From this figure we see that the trends are nearly identical, with a slight difference in values. In fact, the maximum reduction in displacement thickness for this study was $35 \%$ below the baseline value of the same case mentioned above $(60 \mathrm{mph}$, $\left.\mathrm{V}_{\mathrm{E}} / \mathrm{V}_{\infty}=1.24\right)$. Therefore the displacement thickness was reduced more than momentum thickness. In fact, this trend of better reduction in $\delta_{1}$ than $\delta_{2}$ continued throughout the data, but in order to be concise, the remaining $\delta_{1}$ results are omitted from this paper.

\subsubsection{Roughness Study}

Considering roughness has a significant effect in most boundary layer applications it was necessary to understand the effect this parameter may have on the results. Only two cases were studied, a smooth (bare aluminum) case and a case with 40grit sandpaper attached to the cylinder. At the lower rotational velocities $\left(\mathrm{V}_{\mathrm{E}} / \mathrm{V}_{\infty} \leq\right.$ 0.6) it appeared that although the sandpaper case started at a greater disadvantage the 
improvement slope was much greater than the smooth case. However, after a certain rotational velocity was reached, no appreciable improvement was noticed. Figure 21 shows the superiority of the smooth case to be $5-20 \%$ greater than the sandpaper case and continuing to grow as the rotational velocity increases.

When compared to the profiles in Figure 18 of the smooth case, it is evident the sandpaper case reaches a point of no further improvement beyond a rotational velocity of $\mathrm{V}_{\mathrm{E}} / \mathrm{V}_{\infty} \geq 0.6$.

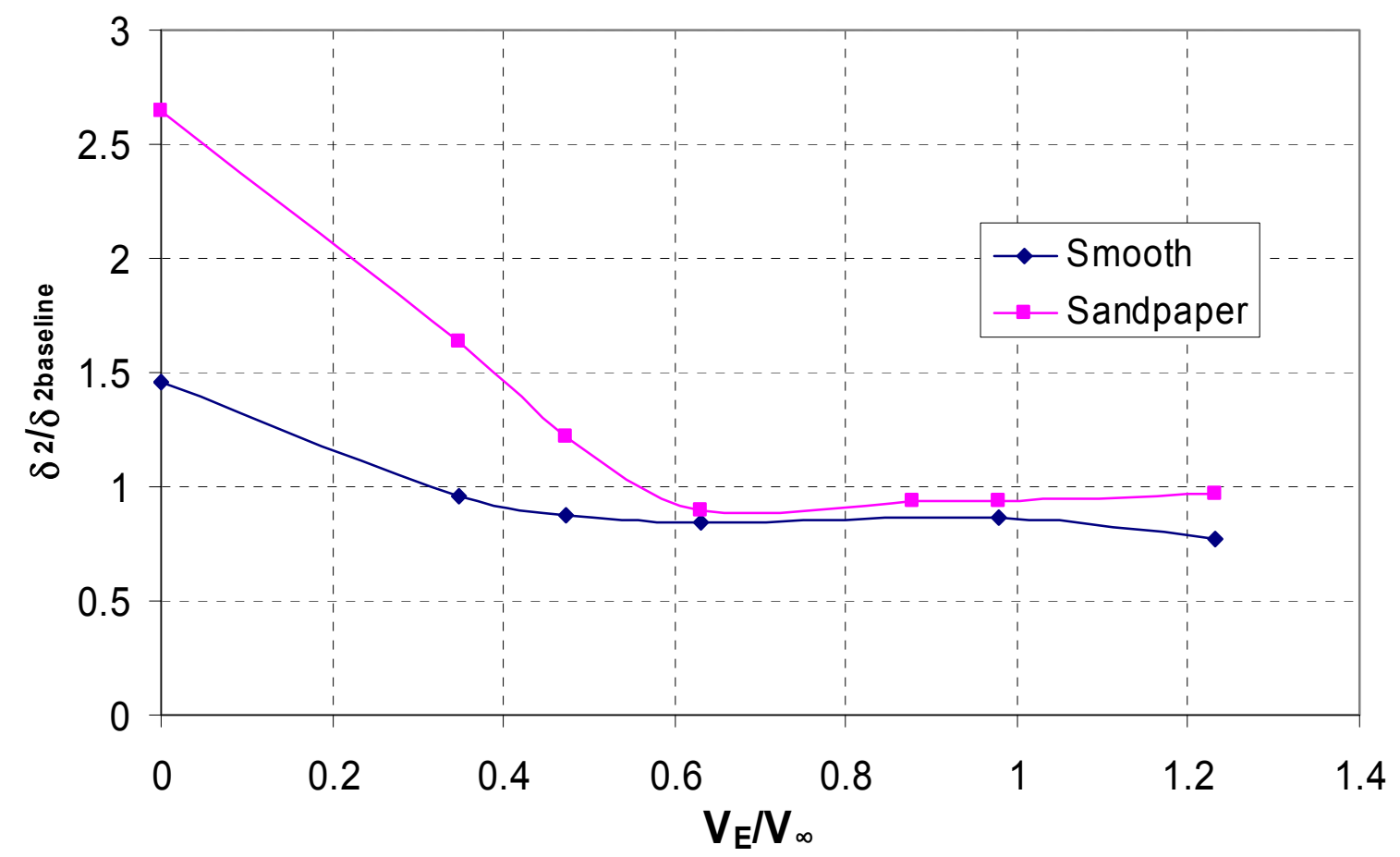

Figure 21: Boundary Layer Thickness: Roughness Effect

Further evidence of this effect can be seen from the total pressure profiles of the sandpaper case in Figure 22. The cause of this behavior is not known, but it could be worthy of further investigation. 


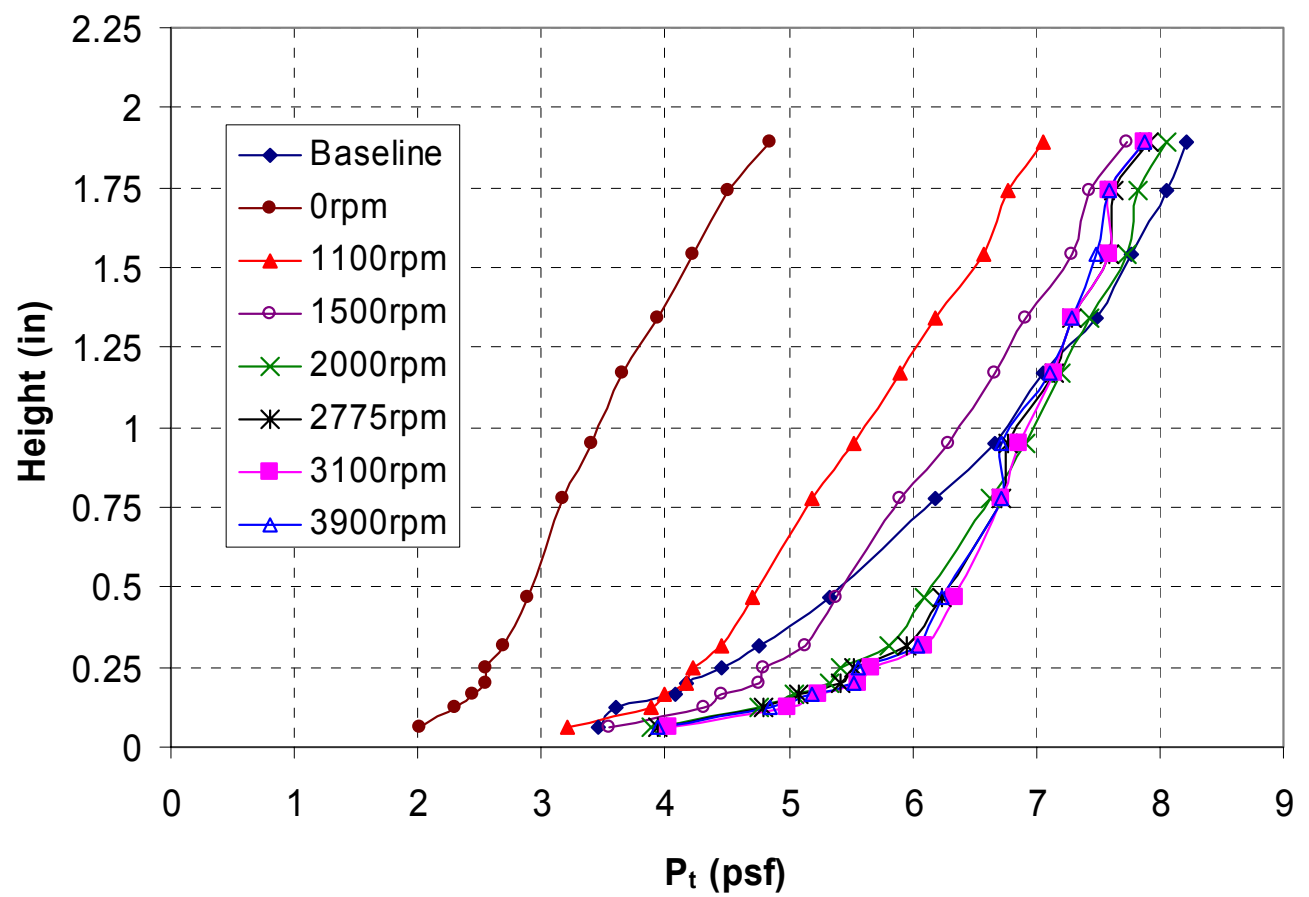

Figure 22: $P_{t}$ Profiles for Sandpaper Case

\subsubsection{Exposed Cylinder Effect}

The amount the cylinder is exposed to the incoming flow was initially thought to play a big role in the reduction of momentum thickness although how was largely unknown. Although that effect would be greatly diminished the induced velocity profile would propagate nonetheless. However, if we remember the dominance of viscous effects in the boundary layer region, the more exposed area in the flow should provide more influence and therefore introduce more energy. Subsequent experimental data for three different exposed heights, h (inches), shown in Figure 23, tends to support the second conclusion. 


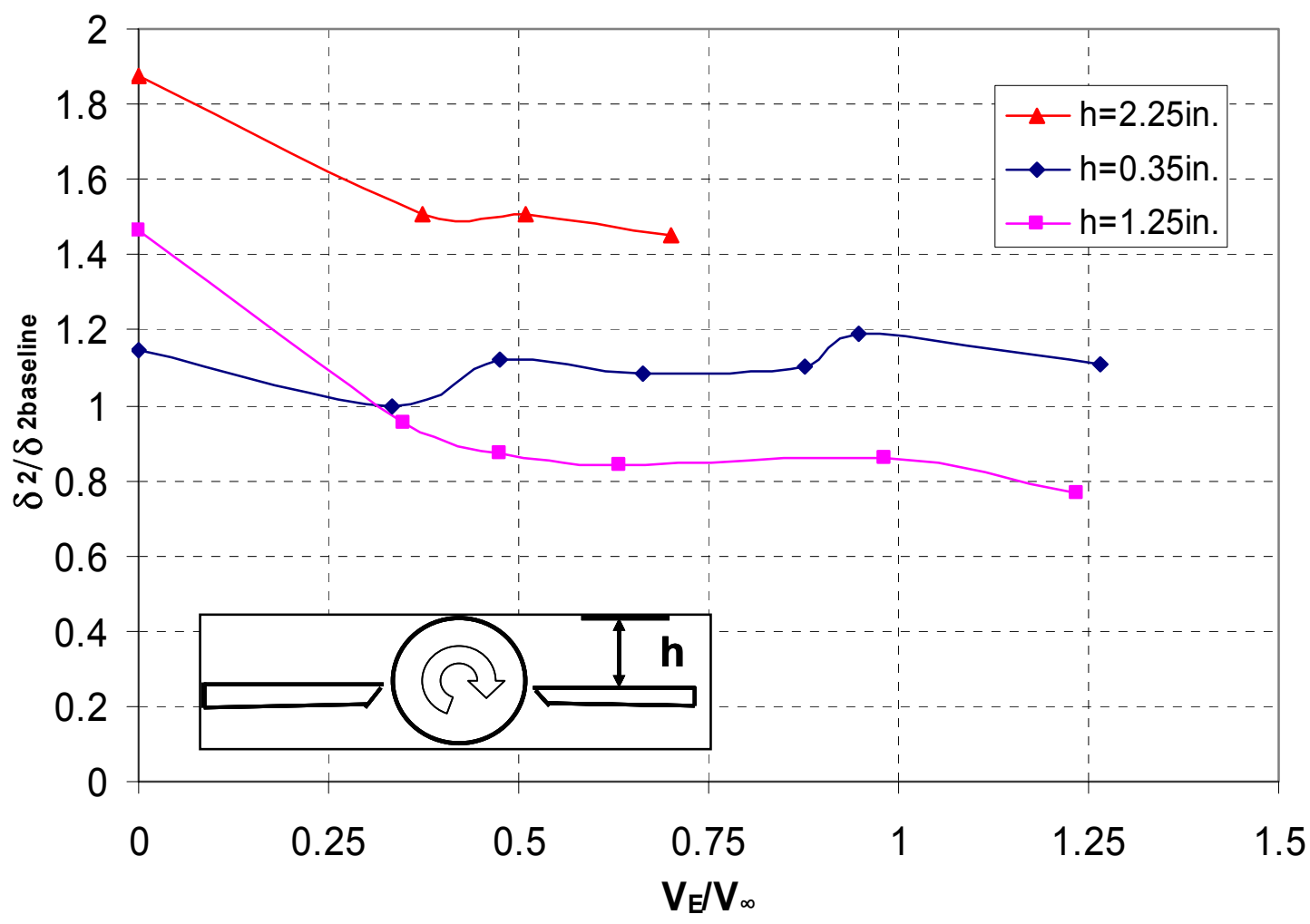

Figure 23: Boundary Layer Thickness: Effect of Exposed Height, h

With almost no effect coming from the lowest value of $\mathrm{h}$, and the greatest improvement found for $\mathrm{h}=1.25 \mathrm{in}$., which is still inside the boundary layer. The largest height, $\mathrm{h}=2.25 \mathrm{in}$., actually puts the cylinder just outside the boundary layer, where viscous effects are no longer dominant and therefore resulting in a less effective solution.

For this sensitivity study, a dimensional analysis was made to in an attempt to find a non-dimensional quantity that would better describe this effect. Different combinations of parameters including the cylinder exposed surface area and equivalent Blasius solution distance were tried unsuccessfully. Without enough data points to discover a clear trend the only conclusion made from this parameter was the placement of the cylinder should be exposed to the flow, but still within the boundary layer. 


\subsubsection{Effect of Brushes}

The brushes used in the BMWT experiment served the same purpose as those in the boundary layer tunnel; reduce the cross-flow between the lower pressure test section and the exterior atmosphere. The brushes used were 1.5in. wide by 59in. long and mounted using nails to the underside of the plywood. Figure 24 gives a close-up view of the brushes themselves.
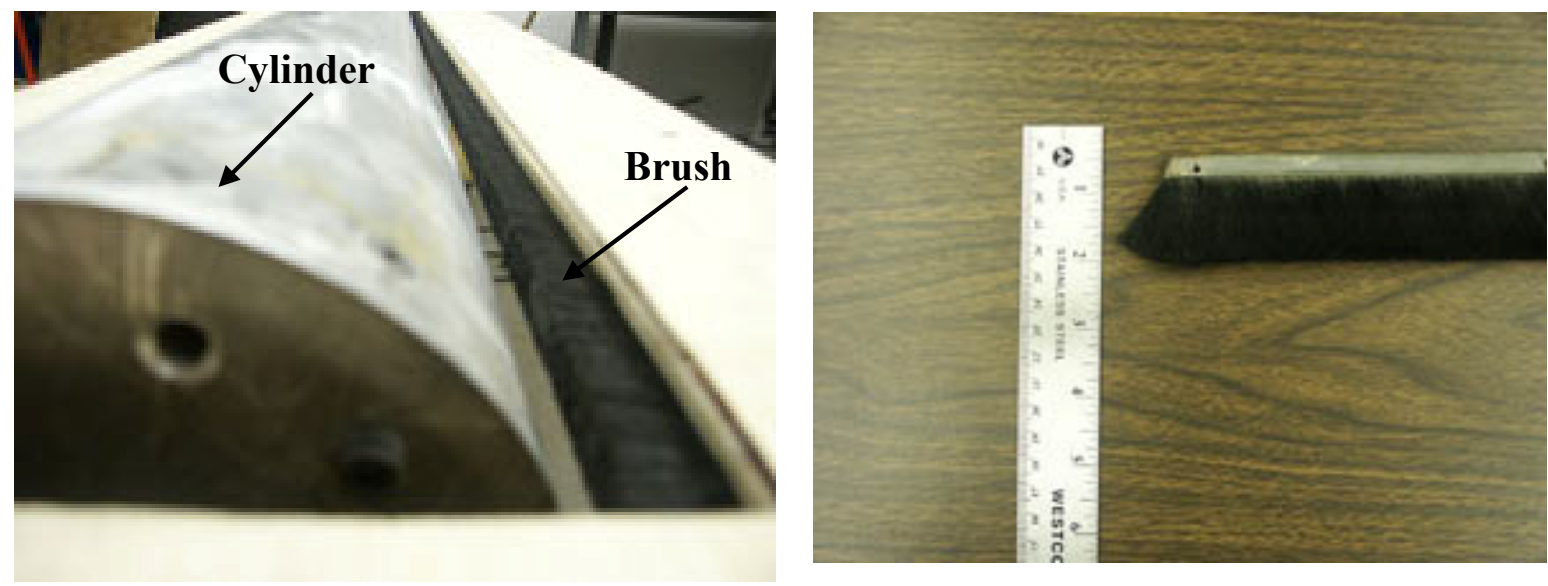

Figure 24: Close-up View of Brushes

Initially the brushes were located to touch the rotating cylinder, but this caused unwanted vibration of the upwind brush. This problem was exacerbated in the sandpaper case. In an attempt to solve this problem some tests were initially performed without the brushes, since no significant problems were noticed in the Boundary Layer Tunnel test. However after reducing and analyzing the data a significant difference was noticed between the profiles with brushes and those without. The next best solution available to solve this problem was to place a small gap ( $\sim 0.125 \mathrm{in}$.$) between the cylinder edge and$ the brushes. Figure 25 shows the difference in momentum thickness, $\delta_{2}$, between the brushed and brushless cases. 


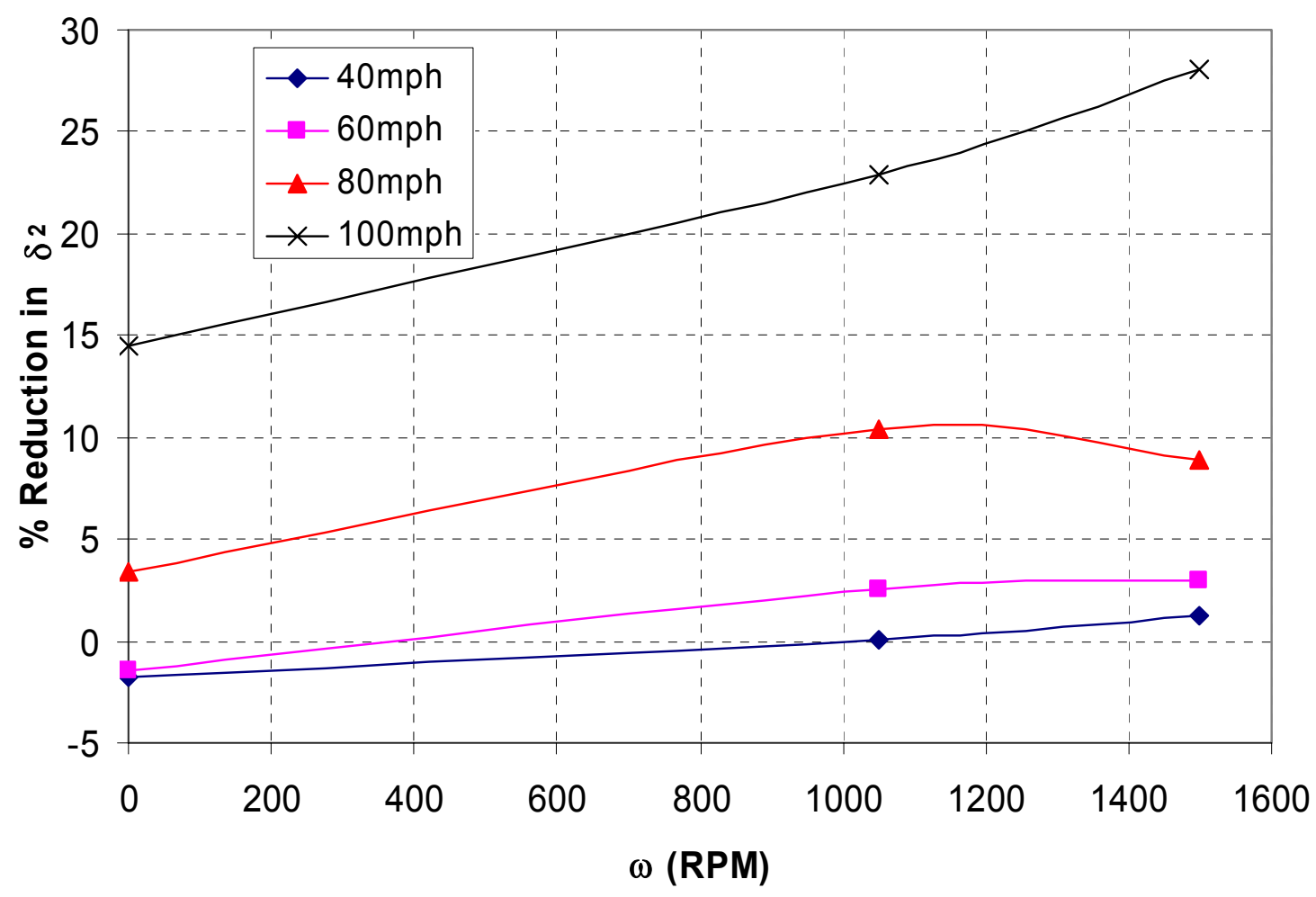

Figure 25: Reduction in Momentum Thickness by Adding Brushes

The values obtained show the brushed case was $5-29 \%$ better than the brushless

case. The effect was more pronounced at the higher tunnel velocities as well as the higher cylinder rotational velocities. There were two data points in the $40 \mathrm{mph}$ and $60 \mathrm{mph}$ cases that were slightly better without brushes at the $\mathrm{V}_{\mathrm{E}} / \mathrm{V}_{\infty}=0$ case. When investigating these differences it was found the static pressure inside the tunnel for these cases was equal to or slightly greater than the outside atmosphere. This would mean any cross-flow would travel from inside the tunnel to outside effectively creating a small suction effect that would assist in energizing the boundary layer. After quantifying this effect the remaining tests were performed using the brushed configuration with the small gaps. 


\subsection{Discussion of Uncertainties}

In this section, the uncertainties present in the data and how these uncertainties were obtained will be discussed. The first approach used to try and estimate the uncertainties was a direct Kline-Polhausen technique. However this method was difficult to implement since most of the data was averaged inside the data collection system, PSI8400 , reasonable standard deviations could not be calculated. In a sense the data were already digitally filtered by the time they reached the CSV file, thereby making the standard deviation values extremely small.

A new approach was adopted that used the available data and some engineering judgment by the author to gather reasonable uncertainties. Throughout testing, a running $\log$ was kept on the accuracy of the measurements taken. From there, perturbations were made to the data to check the uncertainty effects and reasonable methods used to estimate real confidence parameters to support the presented data.

\subsubsection{Cylinder Velocity $\left(V_{E}\right)$ Uncertainty}

The first uncertainty value that will be discussed is cylinder velocity measurements. Cylinder velocity was not difficult to control, although it was manually controlled using the variable alternating current device and its values were read from the multimeter. The variance was estimated to be a maximum of approximately $\pm 5 \mathrm{~Hz}$, which would equate to about $\pm 100 \mathrm{rpm}$. This was considered a reasonable tolerance since the smallest resolvable difference needed in $\omega$ was 500rpm with a nominal difference of 1000rpm between set points. The results also support this tolerance, since a significant change in rotational velocity was needed to produce a small difference in momentum thickness values. 


\subsubsection{Total Pressure Uncertainty}

Next, the uncertainty of pressure measurements was a critical value, since it relates directly to the momentum thickness. This parameter was recorded for a total of 15 seconds (three five-second samples) for each data point, with data being taken and averaged at a much higher rate from the PSI 8400 . The output, however, was only the three averaged samples which would inevitably be averaged together to give one final value of total pressure at each port, for every measurement taken. With only three values a standard deviation calculation does not provide an adequate description of the measurement error. Instead, plots were made, such as in Figure 26, comparing the variation in a profile over the three measured data sets for $\omega=0 \mathrm{rpm}$.

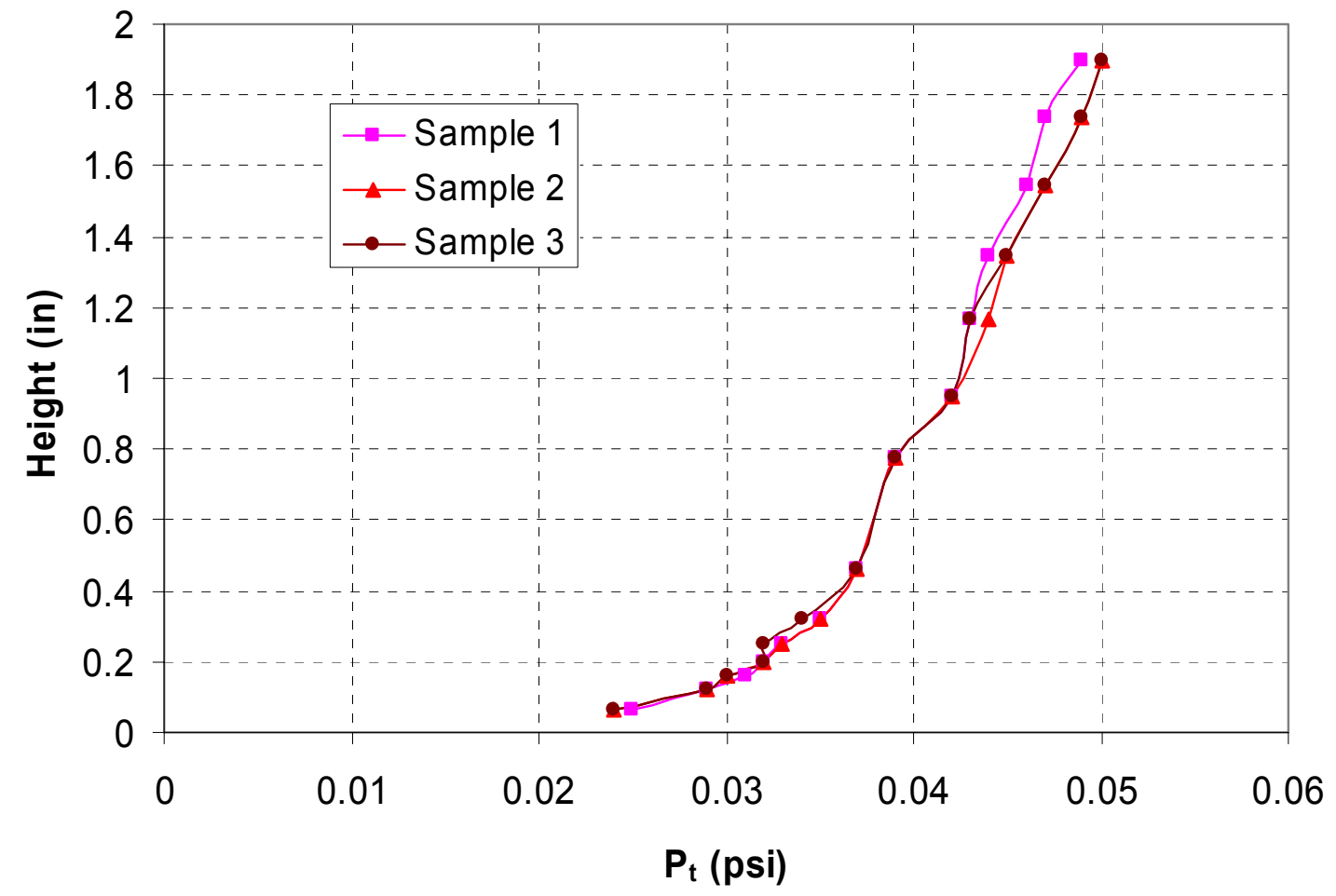

Figure 26: Variation in $P_{t}$ Measurements

The maximum difference between these three profiles is $\pm 0.001 \mathrm{psi}$ which is equivalent to \pm 0.144 psf. Unfortunately, since some of the total pressure plots are trying 
to resolve differences on that same order or magnitude this is too much uncertainty to have good results. After closer inspection, a glitch was found in the output code that only allowed four decimal points accuracy in the raw data file. Since the maximum difference between any of the values obtained was $0.001 \mathrm{psi}$, it can be assumed the actual errors are lower and the differences seen are only rounded up values. With this information a new approach using a weighted variance calculation was used to get a less conservative estimate.

This weighted variance method consisted of four basic steps. First, the average value for each port was calculated using the three known recorded values for each data point. Second, the absolute value of the difference of each individual measurement with the average value calculated in the first step was calculated. This gives us an average and three variance numbers for each port. In the third step, the average value for the three variance numbers was calculated. This is called the local variance value for each of the 15 ports. The final step calculates the average of all the local variances to give a single value for a weighted variance of the total pressure profile. That value came out to be $\pm 0.000317 \mathrm{psi}$ which is equivalent to $\pm 0.045 \mathrm{psf}$ for a rotational velocity value of $\omega=0 \mathrm{rpm}$. While this is still a large uncertainty for the total pressure measurements, it is conservative and less than half the minimum resolved value needed for total pressure profiles. Further analysis showed the uncertainty steadily decreased as the rotational velocity increased to where $\omega=3900 \mathrm{rpm}$ had a weighted variance of $\pm 0.027 \mathrm{psf}$. Now, if that uncertainty of $\pm 0.045 \mathrm{psf}$ trickles down to the calculation of momentum thickness the final variance of $\delta_{2}=0.23 \%$ which is an order of magnitude smaller than the differences 
present in this analysis. Therefore through this method the uncertainty values calculated in total pressure are acceptable for this analysis.

\subsubsection{Tunnel Velocity $\left(V_{\infty}\right)$ Uncertainty}

Another uncertainty value of interest is tunnel velocity uncertainty. This again is a major parameter in the calculation of momentum thickness. So minimizing the error in this measurement is also of critical importance. Fortunately, the upgrades to the BMWT allow the tunnel velocity to be controlled within $\pm 0.1 \mathrm{mph}$ which is approximately $\pm 0.04 \%$ of full scale. This is well within the limits for measuring velocity profiles accurately. As for momentum thickness, a simple perturbation study was performed with the results showing a disturbance of $\pm 0.1 \mathrm{mph}$ to the freestream flow would only change the value of $\delta_{2} \pm 0.000084$ or $\pm 0.05 \%$. These values are an order of magnitude less than the resolution of the momentum thickness value, well within the acceptable range.

\subsubsection{Local Static Pressure Uncertainty}

The final uncertainty of interest in this analysis is the local static pressure uncertainty. Unfortunately in this test a local static pressure was not taken, only the tunnel static pressure was used. At the time this wasn't considered a problem since most of the data is non-dimensionalized with the incoming flow. However, some of the reduced data suggests there could be a static pressure difference behind the exposed cylinder. Figure 18 shows a negative induced total pressure near the edge of the boundary layer. This would seem to contradict the potential theory for a vortex in a uniform flow field without a pressure gradient. It is not unreasonable to hypothesize a situation where part, or all, of the boundary layer rake would be in the viscous wake of the cylinder. Although no separation was seen to reach the boundary layer rake in the 
flow visualization studies, the erratic behavior of the lower port readings (below $\mathrm{h}=0.3 \mathrm{in}$.) could not be explained. Since there are no local readings for static pressure, the presence and therefore uncertainty it would cause cannot be estimated. Also, static pressure is an important sensitivity parameter and could affect the results of velocity profiles.

With the information available there are several positive conclusions that can be made from this problem. First, if there is a static pressure drop, the data would be shifted in a positive way, to reduce the momentum thickness. If we again focus our attention on the data in Figure 18, a shift of total pressure values to the right, thereby satisfying the potential flow theory, would result in improved performance of the technique. Second, since the majority of data presented in this paper was based on total pressure values, which were known explicitly throughout the experiment, the effect of static pressure on the data could be minimized.

Although the unknown problem faced with the potential static pressure difference is concerning the final results show solid, repeatable trends that are all made with relatively high levels of confidence. Therefore, this problem should be noted for further research, but should not be used as a basis for disputing the overall results. 


\subsection{Design Considerations}

From the data gathered in this analysis a set of basic guidelines for the application of this technique was formed. These guidelines are made of conclusions drawn from the presented data as well as lessons learned during testing.

The first thing that must be considered to allow this technique to work to its full potential is maximizing the cylinder's rotational velocity. The data presented in section 5.2.2 shows greater reduction of the boundary layer momentum thickness is possible at higher rotational velocities. Practically, the first way to increase the rotational velocity is to make sure the cylinder is very precisely balanced. The biggest problem in increasing the rotational velocity in this analysis was the harmonic vibrations encountered due to the imprecise construction of the cylinder apparatus. More specifically, the cylinder itself was made of rolled aluminum and the drive shaft from the router motor was simply a bolt instead of a precise metal shaft. Of secondary concern to increasing the rotational velocity is the power of the drive system. The $3.5 \mathrm{Hp}$ router was a good selection for this experiment since it was not heavily taxed, even at the higher $\omega$ values. If higher values can be achieved, the possibility of reaching the quality of $\mathrm{NRC}$ tunnel ${ }^{5}$ is not unrealistic. If the trends from the results of this survey are extrapolated using a curve fit, as in Figure 27 we can see a value of $V_{E} / V_{\infty}$ of 1.5 for the $60 \mathrm{mph}$ case is equal to the $70 \%$ reduction in displacement thickness. Although this is only an extrapolation of the current data, it emphasizes how important it would be to test the higher rotational velocities in order to understand the full behavior of the technique. 


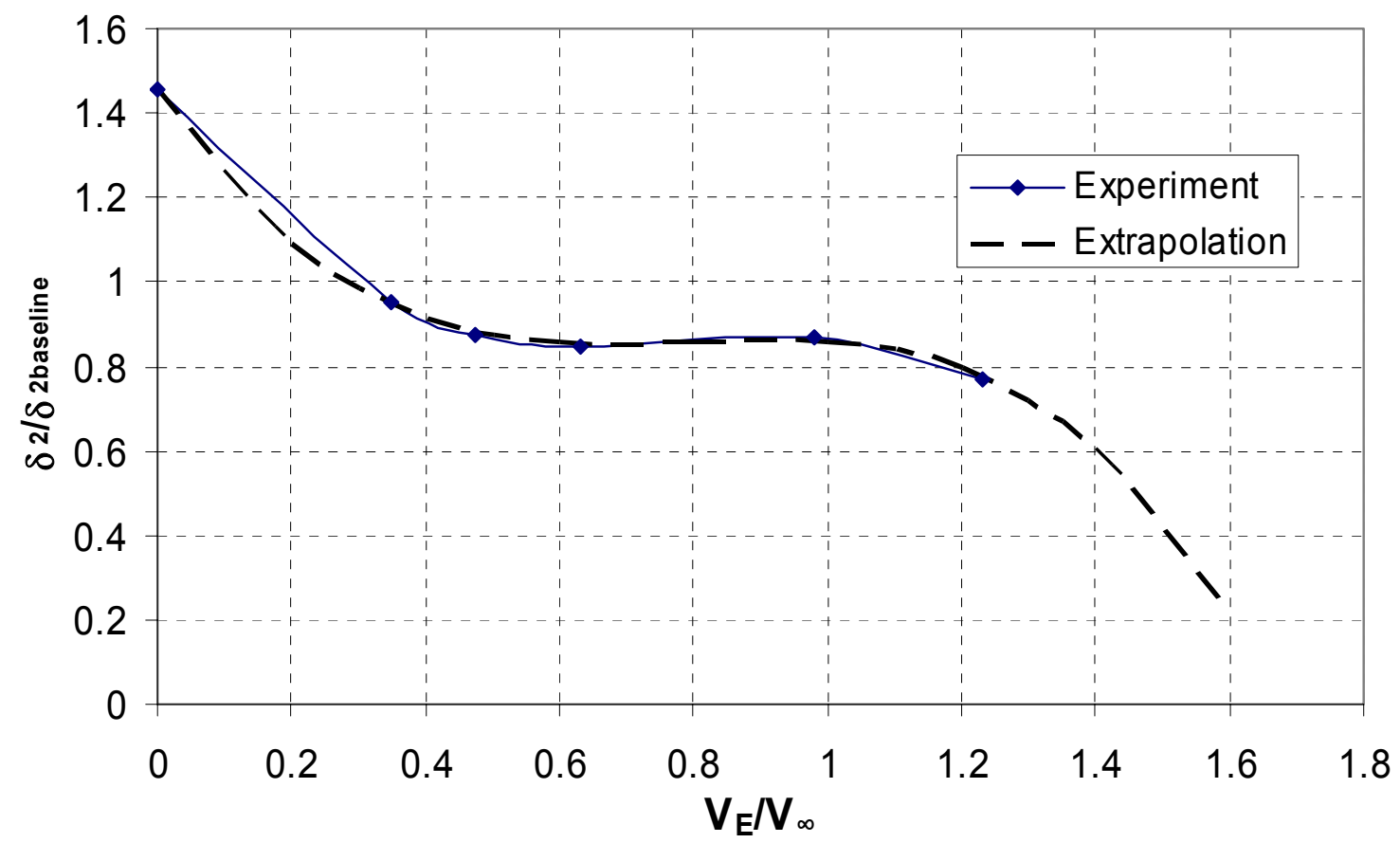

Figure 27: Results for 60mph Case Extrapolated to Higher $V_{E} / V_{\infty}$ Values

Next, the data showed the cylinder must be exposed in the flow in order to reduce the boundary layer momentum thickness. Although there were not enough values gathered to suggest an optimum cylinder height or wetted area some general guidelines were noted. In the cases studied it was apparent the cylinder height should be less than the boundary layer height. The best position tested was a height of approximately $\delta / 2$. Theory also suggests a larger cylinder would provide a greater increment to the momentum introduction in the flow, by increasing effective wetted area of the cylinder.

Another observation showed venting must be reduced as much as possible in order to get the best results. While brushes were implemented during testing, a small gap remained between the rotating cylinder and the surrounding frame. The effect of this gap is not known, but the optimum condition would be a completely sealed setup. This could be incorporated using flexible plastic strips or a more sophisticated set of brushes. 
In general the shape and design of a system like this needs to be made with a great deal of precision since the rotational velocities are so high. Other considerations like room for placement in the wind tunnel may require even higher velocities to compensate for the smaller max cylinder diameter that can be used. Also, controlling the rotational velocities will need to have a feedback controller, since the momentum present in the system requires continual input changes. In the end implementing this technique is still a simpler task than any of the comparable options available today. 


\subsection{Conclusions}

Previous sources have shown the necessity of good boundary layer control systems in order to obtain accurate and useful aerodynamic assessments of ground vehicles. These boundary layer control systems vary widely in cost, complexity, performance, and the theory behind the approach. Most are quite difficult to implement. Therefore if a system is to be designed for a university tunnel such as the Walter $\mathrm{H}$. Beech Memorial Wind Tunnel where cost and complexity must be minimized while still holding to expected standards of such an advanced wind tunnel, a new approach should be sought out. The approach presented in this work is an option that could fill that need.

The rotating cylinder concept was removable, relatively simple to construct, and produced significant reduction in the boundary layer. This approach relies on simple potential flow theory adjusted for viscous effects using documented experimental data. The successful pilot and subsequent full scale tests showed a great deal of promise in being able to modify the boundary layer through the introduction of circulation into the flow. In order to gauge the importance of the parameters involved in this approach sensitivity studies were performed on the different variables.

From these sensitivity studies an overall set of conclusions could be made to assist in future studies and applications. First, the tunnel velocity relates most to the amount of energy lost in the boundary layer. For higher $\mathrm{V}_{\infty}$ values more energy is needed to offset the momentum loss in the flow. Secondly, addition of cylinder surface roughness hinders rather than helps the efficiency of the method. This appears to be due to the drag caused by earlier flow separation over the cylinder. Next, the exposed cylinder height, h, must be below the edge of the boundary layer height. However, there 
is also a point at which the cylinder is not exposed enough to cause a significant effect on the flow. Also a necessity for increased performance is a method to reduce leakage flow from the outside atmosphere and the tunnel test section. While brushes were successfully utilized in this application, other techniques may produce even better results. Finally, the most important parameter needed to reduce the momentum thickness is higher rotational velocities. Finding the practical limit of this parameter will expose the true boundaries of this technique's effectiveness.

While reductions on the order of $29 \%-40 \%$ in momentum thickness and $35 \%$ $45 \%$ in displacement thickness for these tests are a step in the right direction, they are not a replacement for sophisticated rolling roads or continuous suction techniques. However, with some improvement of the apparatus it is reasonable to assume comparable performance to suction systems, such as in the $\mathrm{NRC}^{5}$, where reductions in $\delta_{1}$ on the order of $71 \%$ have been observed. With the information gained from this study it appears this technique is a well-suited candidate for more development. 


\subsection{Recommendations}

The results found during the testing of this technique were very promising. Not only were the boundary layer momentum thickness values reduced on similar scales in two separate studies, but there is still room for even further improvement. There are some further studies, that time would not permit, that would be very beneficial in realizing the optimization of this technique. These recommendations for further study are described in this section.

The first idea relates to the problem encountered with the negative induced total pressure values (obviously incorrect) and unsteady lower boundary layer flow phenomena seen in Figure 18. The work presented in this study indicates this problem is due to static pressure loss caused by flow separation over the cylinder. When considering a way to eliminate this problem a possible solution technique arose. Considering separation is caused by adverse pressure gradients that are too large for the natural energy of the flow to overcome, such as in airfoil design, there needs to be a way of better controlling the pressure recovery region behind the cylinder. If we consider separation of a rotating cylinder will occur somewhere behind the $90^{\circ}$ circumferential location, a design study could create a way to recover this pressure gradient much like in an airfoil. Either geometric (Option A) or active control (Option B) could be used, as shown in Figure 28. While other problems may arise because of this added complexity to the technique, the possible benefits are worth exploring. 


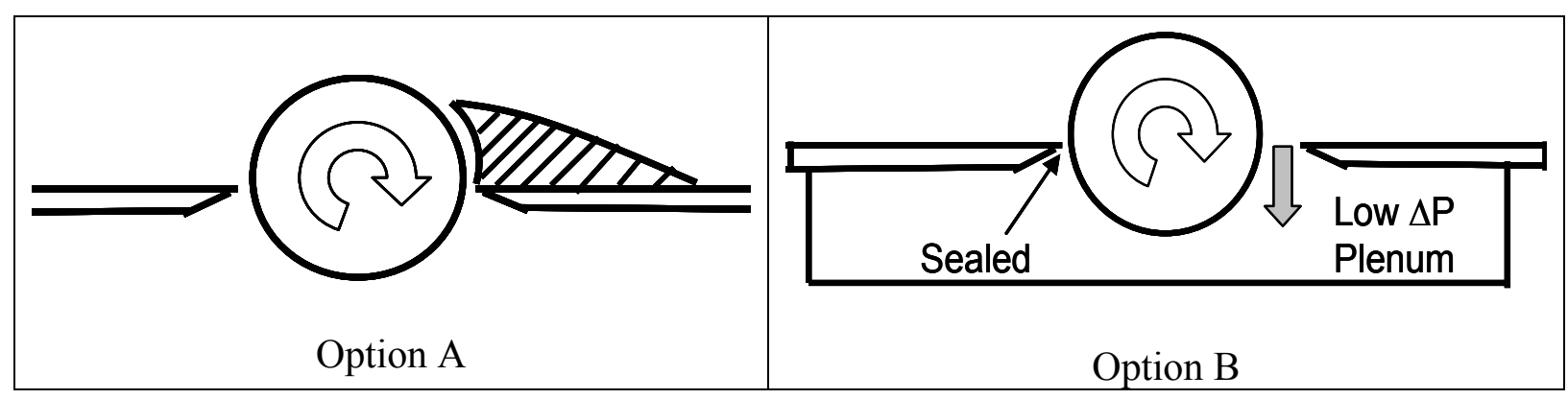

Figure 28: Proposed Pressure Recovery Study Options

The other study worth mentioning again for future consideration is the cylinder radius sensitivity. While this is probably the most difficult parameter to change, it still has an important effect on the results that has not been quantified. To keep a study of this nature feasible a small scale test, utilizing a tunnel like the Boundary Layer Tunnel described in this paper, would almost be required. In this way the problems encountered with a small amount of imbalance will be minimized. From the theory described one would expect a larger cylinder to have the effect of shifting the curve of momentum thickness versus rotational velocity, shown in Figure 19, down thereby increasing the system effectiveness. Once again, experimental results are needed to back this theory up and assess the losses due to viscous effects that the theory is unable to predict.

By exploring these effects as well as extending the range of rotational velocities that can be reached, the capabilities and limitations of this technique can be more fully understood. When this is done, it is likely to show this technique is well suited for the application it was developed. 
LIST OF REFERENCES 
1.) Hucho W.H., Janssen L.J. and Schwartz A.: "The wind tunnel's ground plane boundary layer - Its interference with the flow underneath cars." SAE Paper 750066, February 1975.

2.) Eckert W.T. and Mercker E.: "The Effect of Groundplane Boundary Layer Control on Automotive Testing in a Wind Tunnel.” SAE Paper 880248, 1988.

3.) Hucho, W.H., Aerodynamics of Road Vehicles, 4th Ed., SAE 1998.

4.) Carr, G. and Eckert, W., "A further Evaluation of the Ground-Plane Suction Method for Ground Simulation in Automotive Wind Tunnels", SAE Paper 940418, 1994.

5.) Larose, G.L. and Tanguay, B., "The New Boundary Layer Control System for NRC's 9m x 9m Wind Tunnel," AIAA-2001-0455, 39th Aerospace Sciences Meeting and Exhibit, Reno NV, 8-11 January 2001.

6.) Landman, D., Britcher, C.P., and Martin, P., "A study of Ground Simulation for Wind Tunnel Testing of Full-Scale NASCAR's," 38th Aerospace Sciences Meeting and Exhibit, Reno NV, 10-13 January 2000.

7.) Wickern G., Dietz, S., and Luehrmann, L., "Gradient Effects on Drag Due to Boundary-Layer Suction in Automotive Wind Tunnels," SAE Paper 2003-01-0655, 2003.

8.) Watmuff, J.H., "Instabilities Originating from Suction Holes used for Laminar Flow Control (LFC)," MCAT Institute, NASA-CR-196395, July 1994.

9.) Mercker, E., and Wiedemann, J., "Comparison of Different Ground Simulation Techniques for Use in Automotive Wind Tunnels," SAE Paper 900321, 1990.

10.) Landman, D., Britcher, C.P., and Martin, P., "A study of Ground Simulation for Wind Tunnel Testing of Full-Scale NASCAR's," 38th Aerospace Sciences Meeting and Exhibit, Reno NV, 10-13 January 2000.

11.) Personal correspondence with Mark Gleason, aerodynamics engineer Chrysler Aerodynamics laboratories, from January-March 2005.

12.) Hoerner, S.F., Fluid Dynamic Lift, Hoerner Fluid Dynamics, 1985.

13.) Wichita State University Aerodynamics Laboratories Website, www.niar.twsu.edu/newniar/ researchlabs/ad_windtunnels.asp/, 14 March 2005.

14.) Personal correspondence with William Osmand, former WSU engineering student. 
APPENDIX 


\section{Appendix A: WBMT Boundary Layer Survey Results}

Written By: Thomas Farrell

Supervisor(s): John Laffen \& Eric Clower

Subject: Boundary Layer Survey Results

Summary:

On January 7-8, 2005 a boundary layer survey of the current configuration of the Walter H. Beech Memorial Wind Tunnel was conducted.

The data gathered from this survey using a boundary layer mouse comprised of 15 total pressure tubes with a total height of 1.89 inches and a pitot-static tube placed a safe distance away at a height of 6.0 inches to record the local freestream velocity. The exact spacing of each probe was measured and recorded in the reduced data file. The tunnel was controlled in MPH mode and all pressure data was recorded using the PSI 8400 system. A total of 10 runs including eight data points each $(25,50,75,100,125,150$, $175 \& 200 \mathrm{mph}$ ) were performed with Run \#2 data deemed invalid when the door was opened to find the boundary layer mouse had moved from its initial position. The remaining nine runs corresponded to the following tunnel locations:
Run \#1: Forward / Center
Run \#7: Forward / Infield
Run \#3: Center / Center
Run \#8: Forward / Outboard
Run \#4: Aft / Center
Run \#9: Center / Outboard
Run \#5: Aft / Infield
Run \#10: Aft / Outboard

Run \#6: Center / Infield

Where the location Forward corresponds to the first row of fasteners at the front of the test section, Center corresponds to $6.0 \mathrm{ft}$ aft of the beginning of the test section, and $\mathrm{Aft}$ corresponds to the final row of fasteners in the aft of the test section. The Infield location is 16 inches from the infield fillet, Center is located on the centerline of the tunnel, and Outboard is 16 inches from the outboard fillet location.

\section{Observations:}

The boundary layer thickness was defined using White ${ }^{1}$ as $95 \%$ of the local freestream velocity. Using this definition the average boundary layer thickness was as shown in Table A1.

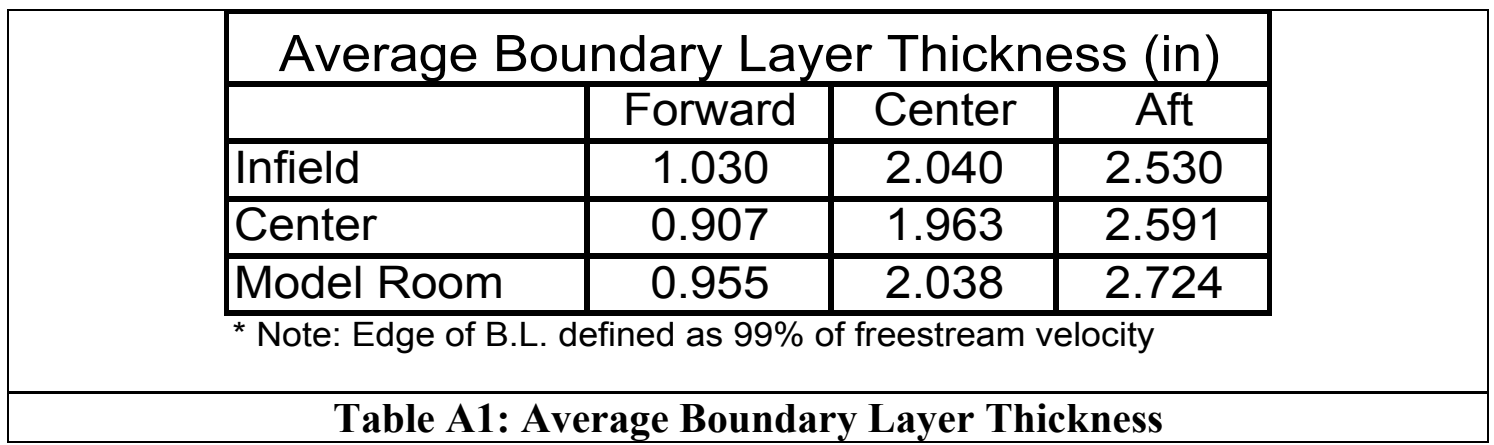


A full breakdown of the values obtained is presented on the below. Any value exceeding the total height of the probe was extrapolated using a second order polynomial fit in

Excel.

\section{Boundary Layer Thickness (in)}

\begin{tabular}{|c|c|c|}
\hline \multicolumn{3}{|c|}{ Location: Fwd/Infield } \\
\hline \multirow{2}{*}{$\begin{array}{c}\text { Tunnel } V_{\infty} \\
\text { (mph) }\end{array}$} & \multicolumn{2}{|c|}{$\%$ of Local Vavg } \\
\hline & & \\
\hline 25 & 0.75 & Unknown \\
\hline 50 & 0.74 & 1.24 \\
\hline 75 & 0.69 & 1.1 \\
\hline 100 & 0.68 & 1.06 \\
\hline 125 & 0.65 & 0.99 \\
\hline 150 & 0.64 & 0.97 \\
\hline 175 & 0.62 & 0.93 \\
\hline 200 & 0.61 & 0.92 \\
\hline AVG & $\overline{0.673}$ & 1.03 \\
\hline
\end{tabular}

\begin{tabular}{|c|c|c|}
\hline \multicolumn{3}{|c|}{ Location: Center/Infield } \\
\hline \multirow{2}{*}{$\begin{array}{c}\text { Tunnel Vo } \\
\text { (mph) }\end{array}$} & \multicolumn{2}{c|}{$\%$ of Local Vavg } \\
$95 \%$ & $99 \%$ \\
\hline 25 & Unknown & Unknown \\
\hline 50 & 1.42 & Unknown \\
\hline 75 & 1.395 & Unknown \\
\hline 100 & 1.392 & 2.1 \\
\hline 125 & 1.39 & 2.09 \\
\hline 150 & 1.34 & 2.01 \\
\hline 175 & 1.33 & 2.01 \\
\hline 200 & 1.31 & 1.99 \\
\hline AVG & $\mathbf{1 . 3 6 8}$ & $\mathbf{2 . 0 4}$ \\
\hline
\end{tabular}

\begin{tabular}{|c|c|c|}
\hline \multicolumn{3}{|c|}{ Location: Aft/Infield } \\
\hline \multirow{2}{*}{$\begin{array}{c}\text { Tunnel } \mathrm{V}^{\infty} \\
\text { (mph) }\end{array}$} & $\begin{array}{c}\% \text { of Local Vavg } \\
95 \%\end{array}$ & $99 \%$ \\
\hline 25 & Unknown & Unknown \\
\hline 50 & 2.04 & 2.963 \\
\hline 75 & 2.04 & 2.797 \\
\hline 100 & 2.02 & 2.087 \\
\hline 125 & 2 & 2.344 \\
\hline 150 & 1.9 & 2.7 \\
\hline 175 & 1.9 & 2.676 \\
\hline 200 & 1.85 & 2.1418 \\
\hline AVG & $\mathbf{1 . 9 6 4}$ & $\mathbf{2 . 5 3 0}$ \\
\hline
\end{tabular}

\begin{tabular}{|c|c|c|}
\hline \multicolumn{3}{|c|}{ Location: Fwd/Center } \\
\hline $\begin{array}{c}\text { Tunnel Vo } \\
\text { (mph) }\end{array}$ & $\begin{array}{c}\% \text { of Local Vavg } \\
95 \%\end{array}$ & $99 \%$ \\
\hline 25 & Unknown & Unknown \\
\hline 50 & 0.74 & 1.25 \\
\hline 75 & 0.69 & 0.96 \\
\hline 100 & 0.66 & 0.86 \\
\hline 125 & 0.63 & 0.86 \\
\hline 150 & 0.61 & 0.84 \\
\hline 175 & 0.575 & 0.78 \\
\hline 200 & 0.57 & 0.8 \\
\hline AVG & $\mathbf{0 . 6 3 9}$ & $\mathbf{0 . 9 0 7}$ \\
\hline
\end{tabular}

\begin{tabular}{|c|c|c|}
\hline \multicolumn{3}{|c|}{ Location: Center/Center } \\
\hline $\begin{array}{c}\text { Tunnel } V_{\infty} \\
(\mathrm{mph})\end{array}$ & $\begin{array}{c}\% \text { of Lo } \\
95 \%\end{array}$ & $\begin{array}{c}\text { cal Vavg } \\
99 \%\end{array}$ \\
\hline 25 & \begin{tabular}{|l} 
Unknown \\
\end{tabular} & Unknown \\
\hline 50 & 1.43 & 2.01 \\
\hline 75 & 1.43 & 2 \\
\hline 100 & 1.41 & 1.98 \\
\hline 125 & 1.41 & 1.98 \\
\hline 150 & 1.345 & 1.94 \\
\hline 175 & 1.32 & 1.93 \\
\hline 200 & 1.29 & 1.9 \\
\hline AVG & 1.376 & 1.963 \\
\hline
\end{tabular}

\begin{tabular}{|c|c|c|}
\hline \multicolumn{3}{|c|}{ Location: Aft/Center } \\
\hline $\begin{array}{c}\text { Tunnel V } \infty \\
\text { (mph) }\end{array}$ & \multicolumn{2}{c|}{$\begin{array}{c}\text { \% of Local Vavg } \\
95 \%\end{array}$} \\
\hline 25 & Unknown & Unknown \\
\hline 50 & 2.1 & 2.09 \\
\hline 75 & 2.04 & 2.867 \\
\hline 100 & 2.04 & 2.3435 \\
\hline 125 & 1.98 & 2.6945 \\
\hline 150 & 1.98 & 2.5845 \\
\hline 175 & 1.84 & 2.868 \\
\hline 200 & 1.84 & 2.6894 \\
\hline AVG & $\mathbf{1 . 9 7 4}$ & $\mathbf{2 . 5 9 1}$ \\
\hline
\end{tabular}

\begin{tabular}{|c|c|c|}
\hline \multicolumn{3}{|c|}{ Location: Fwd/Outbd. } \\
\hline $\begin{array}{c}\text { Tunnel } V_{\infty} \\
(\mathrm{mph})\end{array}$ & $\begin{array}{c}\% \text { of } L c \\
95 \%\end{array}$ & $\begin{array}{c}\text { cal Vavg } \\
99 \%\end{array}$ \\
\hline 25 & 0.75 & Unknown \\
\hline 50 & 0.75 & Unknown \\
\hline 75 & 0.69 & 1.05 \\
\hline 100 & 0.65 & 0.97 \\
\hline 125 & 0.645 & 0.97 \\
\hline 150 & 0.62 & 0.95 \\
\hline 175 & 0.61 & 0.9 \\
\hline 200 & 0.61 & 0.89 \\
\hline AVG & 0.666 & 0.955 \\
\hline
\end{tabular}

\begin{tabular}{|c|c|c|}
\hline \multicolumn{3}{|c|}{ Location: Center/Outbd. } \\
\hline $\begin{array}{c}\text { Tunnel Vo } \\
\text { (mph) }\end{array}$ & \multicolumn{2}{c|}{$\begin{array}{c}\text { \% of Local Vavg } \\
95 \%\end{array}$} \\
\hline 25 & Unknown & Unknown \\
\hline 50 & 1.61 & Unknown \\
\hline 75 & 1.51 & 2.09 \\
\hline 100 & 1.49 & 2.06 \\
\hline 125 & 1.47 & 2.05 \\
\hline 150 & 1.45 & 2.04 \\
\hline 175 & 1.43 & 2.01 \\
\hline 200 & 1.4 & 1.98 \\
\hline AVG & $\mathbf{1 . 4 8}$ & $\mathbf{2 . 0 3 8}$ \\
\hline
\end{tabular}

\begin{tabular}{|c|c|c|}
\hline \multicolumn{3}{|c|}{ Location: Aft/Outbd. } \\
\hline $\begin{array}{c}\text { Tunnel V } \infty \\
\text { (mph) }\end{array}$ & $\begin{array}{c}\% \text { of Local Vavg } \\
95 \%\end{array}$ & $99 \%$ \\
\hline 25 & Unknown & Unknown \\
\hline 50 & 2.14 & 2.34 \\
\hline 75 & 2.14 & 3.22 \\
\hline 100 & 2.13 & 3.329 \\
\hline 125 & 2.13 & 2.856 \\
\hline 150 & 2.08 & 2.4473 \\
\hline 175 & 2.07 & 2.34 \\
\hline 200 & 2.07 & 2.538 \\
\hline AVG & $\mathbf{2 . 1 0 9}$ & $\mathbf{2 . 7 2 4}$ \\
\hline \multicolumn{3}{|c}{} \\
\hline
\end{tabular}

